\title{
Evidence for perchlorates and the origin of chlorinated hydrocarbons detected by SAM at the Rocknest aeolian deposit in Gale Crater
}

\author{
Daniel P. Glavin, ${ }^{1}$ Caroline Freissinet, ${ }^{2}$ Kristen E. Miller, ${ }^{3}$ Jennifer L. Eigenbrode, ${ }^{1}$ \\ Anna E. Brunner, ${ }^{1,4}$ Arnaud Buch, ${ }^{5}$ Brad Sutter, ${ }^{6,7}$ P. Douglas Archer Jr., ${ }^{7}$ \\ Sushil K. Atreya ${ }^{8}$ William B. Brinckerhoff, ${ }^{1}$ Michel Cabane, ${ }^{9}$ Patrice Coll, ${ }^{10}$ \\ Pamela G. Conrad, ${ }^{1}$ David Coscia,${ }^{9}$ Jason P. Dworkin, ${ }^{1}$ Heather B. Franz, ${ }^{1,11}$ \\ John P. Grotzinger, ${ }^{12}$ Laurie A. Leshin, ${ }^{13}$ Mildred G. Martin, ${ }^{1,14}$ Christopher McKay, ${ }^{15}$ \\ Douglas W. Ming, ${ }^{7}$ Rafael Navarro-González, ${ }^{16}$ Alexander Pavlov, ${ }^{1}$ Andrew Steele, ${ }^{17}$ \\ Roger E. Summons, ${ }^{3}$ Cyril Szopa, ${ }^{9}$ Samuel Teinturier, ${ }^{9}$ and Paul R. Mahaffy ${ }^{1}$
}

Received 13 May 2013; revised 23 July 2013; accepted 15 August 2013; published 1 October 2013.

[1] A single scoop of the Rocknest aeolian deposit was sieved $(<150 \mu \mathrm{m})$, and four separate sample portions, each with a mass of $\sim 50 \mathrm{mg}$, were delivered to individual cups inside the Sample Analysis at Mars (SAM) instrument by the Mars Science Laboratory rover's sample acquisition system. The samples were analyzed separately by the SAM pyrolysis evolved gas and gas chromatograph mass spectrometer analysis modes. Several chlorinated hydrocarbons including chloromethane, dichloromethane, trichloromethane, a chloromethylpropene, and chlorobenzene were identified by SAM above background levels with abundances of $\sim 0.01$ to $2.3 \mathrm{nmol}$. The evolution of the chloromethanes observed during pyrolysis is coincident with the increase in $\mathrm{O}_{2}$ released from the Rocknest sample and the decomposition of a product of $\mathrm{N}$-methyl- $\mathrm{N}$-(tert-butyldimethylsilyl)-trifluoroacetamide (MTBSTFA), a chemical whose vapors were released from a derivatization cup inside SAM. The best candidate for the oxychlorine compounds in Rocknest is a hydrated calcium perchlorate $\left(\mathrm{Ca}\left(\mathrm{ClO}_{4}\right)_{2} \cdot \mathrm{nH}_{2} \mathrm{O}\right)$, based on the temperature release of $\mathrm{O}_{2}$ that correlates with the release of the chlorinated hydrocarbons measured by SAM, although other chlorine-bearing phases are being considered. Laboratory analog experiments suggest that the reaction of Martian chlorine from perchlorate decomposition with terrestrial organic carbon from MTBSTFA during pyrolysis can explain the presence of three chloromethanes and a chloromethylpropene detected by SAM.

Chlorobenzene may be attributed to reactions of Martian chlorine released during pyrolysis with terrestrial benzene or toluene derived from 2,6-diphenylphenylene oxide (Tenax) on the SAM hydrocarbon trap. At this time we do not have definitive evidence to support a nonterrestrial carbon source for these chlorinated hydrocarbons, nor do we exclude the possibility that future SAM analyses will reveal the presence of organic compounds native to the Martian regolith.

Citation: Glavin, D. P., et al. (2013), Evidence for perchlorates and the origin of chlorinated hydrocarbons detected by SAM at the Rocknest aeolian deposit in Gale Crater, J. Geophys. Res. Planets, 118, 1955-1973, doi:10.1002/jgre.20144.

\footnotetext{
${ }^{1}$ Solar System Exploration Division, NASA Goddard Space Flight Center, Greenbelt, Maryland, USA.

${ }^{2}$ NASA Postdoctoral Program, NASA Goddard Space Flight Center, Greenbelt, Maryland, USA.

${ }^{3}$ Department of Earth, Atmospheric and Planetary Sciences, Massachusetts Institute of Technology, Cambridge, Massachusetts, USA.

${ }^{4}$ Center for Research and Exploration in Space Science \& Technology, Department of Astronomy, University of Maryland, College Park, Maryland, USA.

${ }^{5}$ Laboratoire Génie des Procédés et Matériaux, Ecole Centrale Paris, Chatenay-Malabry, France.

${ }^{6}$ Jacobs Technology-ESCG, Houston, Texas, USA.

${ }^{7}$ Astromaterials Research and Exploration Science Directorate, NASA Johnson Space Center, Houston, Texas, USA.
}

Corresponding author: D. P. Glavin, Solar System Exploration Division, NASA Goddard Space Flight Center, 8800 Greenbelt Road, Code 699, Greenbelt, MD 20771, USA. (daniel.p.glavin@nasa.gov)

(C2013. American Geophysical Union. All Rights Reserved. 2169-9097/13/10.1002/jgre.20144
${ }^{8}$ Department of Atmospheric, Oceanic and Space Sciences, University of Michigan, Ann Arbor, Michigan, USA.

${ }^{9}$ Laboratoire Atmosphères, Milieux, Observations Spatiales, Univ. Pierre et Marie Curie, Univ. Versailles Saint-Quentin \& Centre National de la Recherche Scientifique, Paris, France.

${ }^{10}$ Laboratoire Interuniversitaire des Systèmes Atmosphériques, Univ. Paris-Est Créteil, Univ. Denis Diderot \& CNRS, Créteil, France.

${ }^{11}$ Center for Research and Exploration in Space Science \& Technology, University of Maryland, Baltimore County, Baltimore, Maryland, USA.

${ }^{12}$ Division of Geological and Planetary Sciences, California Institute of Technology, Pasadena, California, USA.

${ }^{13}$ Department of Earth \& Environmental Science and School of Science, Rensselaer Polytechnic Institute, Troy, New York, USA.

${ }^{14}$ Department of Chemistry, Catholic University of America, Washington, District of Columbia, USA.

${ }^{15}$ Space Science Division, NASA Ames Research Center, Moffett Field, California, USA.

${ }^{16}$ Instituto de Ciencias Nucleares, Universidad Nacional Autónoma de México, Ciudad Universitaria, Mexico City, Mexico.

${ }^{17}$ Geophysical Laboratory, Carnegie Institution of Washington, Washington, District of Columbia, USA. 


\section{Introduction}

[2] The exploration of habitable environments on Mars, including an assessment of the preservation potential for organic compounds of either abiotic or biological origins in Martian rock, regolith fines, and the atmosphere, is one of the key goals of the Mars Science Laboratory (MSL) mission which landed the Curiosity Rover in Gale Crater $\left(4.6^{\circ} \mathrm{S}\right.$, $137.4^{\circ} \mathrm{E}$ ) on 6 August 2012 [Grotzinger et al., 2012]. The Curiosity rover contains the Sample Analysis at Mars (SAM) instrument suite [Mahaffy et al., 2012] that is conducting the most extensive search for volatiles and organic compounds in the Martian atmosphere and surface regolith since the Viking missions. Even in the absence of indigenous biological or abiotic organic chemistry on Mars, exogenous organic matter should have accumulated on the Martian surface due to the continuous micrometeorite influx. It has been estimated that the Martian soil could contain up to 60 parts per million (ppm) of organic carbon from meteoritic sources [Steininger et al., 2012], based on calculations of the amount of meteoritic contribution to the Martian soil [Flynn and Mckay, 1990] and assuming a constant mass influx during the entire Martian history, no degradation of the organic material over time, and efficient mixing of a $100 \mathrm{~m}$ deep regolith, although some degradation of meteoritic organic matter on the Martian surface is inevitable given the radiation and oxidative environment [Biemann et al., 1977; Moores and Schuerger, 2012; Pavlov et al., 2012].

[3] One of the major goals of the Viking missions was to determine whether or not organic compounds, of either biologic or abiotic origins, were present on the surface of Mars. In 1976 the Viking Landers carried out a broad and sensitive search for organic compounds and inorganic volatiles in two surface (upper $10 \mathrm{~cm}$ ) samples collected at two different landing sites (VL-1: Chryse Planitia, $22.7^{\circ} \mathrm{N}$, 48. $2^{\circ} \mathrm{W}$; VL-2: Utopia Planitia, $\left.48.3^{\circ} \mathrm{N}, 226.0^{\circ} \mathrm{W}\right)$ using a thermal volatilization gas chromatograph mass spectrometer (TV-GCMS) instrument [Biemann et al., 1976; Biemann et al., 1977]. After heating the surface samples, two simple chlorinated hydrocarbons, chloromethane $\left(\mathrm{CH}_{3} \mathrm{Cl}\right)$ and dichloromethane $\left(\mathrm{CH}_{2} \mathrm{Cl}_{2}\right)$, were identified by the Viking GCMS instruments; however, their presence was attributed to terrestrial contamination in the instruments [Biemann et al., 1977]. The results from the Viking Biology Experiments [Klein, 1978; Klein et al., 1972] and the lack of GCMS evidence for nonterrestrial organic carbon at either Viking landing site [Biemann et al., 1976; Biemann et al., 1977] led to speculation that chemical oxidation processes [Biemann et al., 1977; Chun et al., 1978; Encrenaz et al., 2004; Oyama et al., 1977; Yen et al., 2000] and/or ultraviolet and ionizing radiation [Moores and Schuerger, 2012; Oró and Holzer, 1979; Stalport et al., 2009; ten Kate et al., 2005] could have either destroyed or transformed the organic material into forms that are not readily detectable by thermal volatilization techniques [Benner et al., 2000].

[4] In 2008, chemical analysis of soluble salts in the Martian regolith carried out by the Wet Chemistry Laboratory (WCL) on the Phoenix Lander (Green Valley, $\left.68.2^{\circ} \mathrm{N}, 125.9^{\circ} \mathrm{W}\right)$ identified perchlorate anion $\left(\mathrm{ClO}_{4}{ }^{-}\right)$at the 0.4 to $0.6 \mathrm{wt} \%$ level [Hecht et al., 2009], an amount of perchlorate that only occurs naturally at similar levels on Earth in specific nitrate ores from the Atacama Desert
[Ericksen, 1983]. The Phoenix Thermal and Evolved Gas Analyzer provided supporting evidence for the presence of perchlorate based on the temperature of release of $\mathrm{O}_{2}$ during thermal volatilization of the samples [Boynton et al., 2009; Hecht et al., 2009]. The discovery of perchlorate on Mars by Phoenix prompted several groups to revisit the origin of the chlorinated hydrocarbons detected by Viking. Although perchlorates were not identified at the Viking landing sites, laboratory TV-GCMS experiments have demonstrated that both chloromethane and dichloromethane can be produced from organic compounds present in terrestrial Mars analog soils from the Atacama Desert when heated at $500^{\circ} \mathrm{C}$ in the presence of magnesium perchlorate [Navarro-González et al., 2010]. Based on these experimental laboratory results and kinetic models, Navarro-González et al. [2010] suggested that there could have been parts per million levels of Martian organic carbon at the Viking landing sites based on the abundances of chloromethanes detected after pyrolysis of the Viking soils. This hypothesis has been challenged [Biemann and Bada, 2011] and debated [Navarro-González and Mckay, 2011].

[5] Here we report on the results from the SAM evolved gas analysis (EGA) and gas chromatograph mass spectrometer (GCMS) experiments on samples from the Rocknest aeolian deposit $\left(4.590^{\circ} \mathrm{S}, 137.448^{\circ} \mathrm{E}\right)$ in Gale Crater, the first solid samples analyzed by SAM on Mars. An overview of the SAM volatile and isotopic analyses of the Rocknest fines has been published recently [Leshin et al., 2013]. Companion papers in this issue will go into greater depth on the possible sources of $\mathrm{H}_{2} \mathrm{O}, \mathrm{CO}_{2}$, and other trace species evolved from Rocknest [Archer Jr. et al., 2013] and the origin of sulfur-bearing gases detected by SAM [McAdam et al., 2013]. In this paper we focus on the suite of chlorinated hydrocarbons identified by SAM and their potential origins, the evidence for perchlorate or other oxychlorine salts in the Rocknest fines, implications of the presence of perchlorates for the extraction of organic compounds by high temperature pyrolysis, and future strategies for in situ organic detection on Mars.

\section{Instrumentation}

\subsection{Sample Processing}

[6] The first scoops from the Rocknest aeolian deposit were used to clean the interior surfaces of the MSL rover's Sample Acquisition, Sample Processing, and Handling (SA/ $\mathrm{SPaH})$ system hardware prior to sample delivery to SAM. Aliquots of sieved $(<150 \mu \mathrm{m})$ fines from the third, fourth, and fifth scoops of Rocknest were delivered directly to the Chemistry and Mineralogy (CheMin) instrument for X-ray diffraction (XRD) and X-ray fluorescence (XRF) measurements. SAM analyzed one empty cup (blank) and four separate sieved $(<150 \mu \mathrm{m})$ and portioned $\left(<76 \mathrm{~mm}^{3}\right)$ samples from the fifth Rocknest scoop taken on Sol 93 (9 November 2012) that were delivered by SA/SPaH directly to individual SAM quartz glass cups on Sols 93, 96, 99, and 117. The mass of the individual Rocknest portions delivered to SAM was not measured in situ. However, based on the volume of sample per portion delivered during repeated experimental tests on Earth with analog materials using the MSL SA/SPaH testbed and theoretical models to approximate the behavior of the $\mathrm{SA} / \mathrm{SPaH}$ system in the Martian environment, a mass 


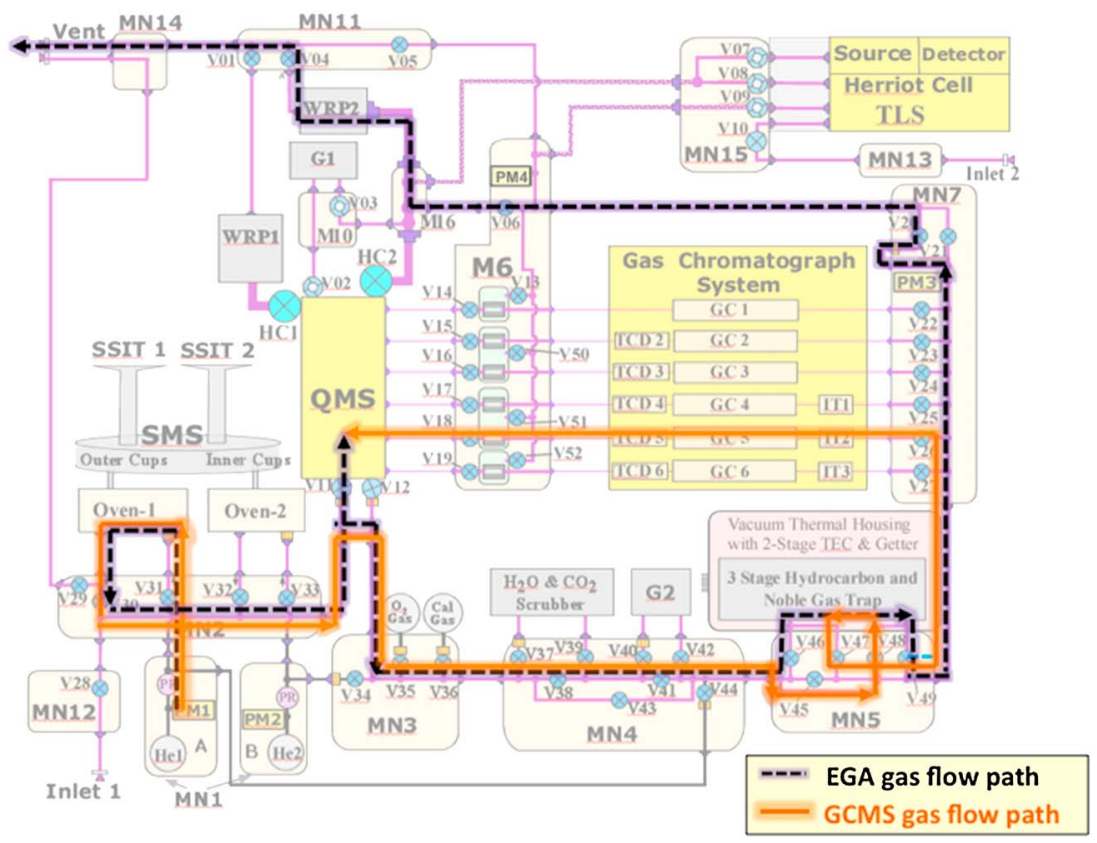

Figure 1. The SAM gas flow diagram showing the helium gas flow paths in both EGA (purple dash) and GCMS modes (orange line). Major components shown include the quadrupole mass spectrometer (QMS), the gas chromatograph system including six columns (GCx), three injection traps (ITx), and five thermal conductivity detectors (TCDx), the tunable laser spectrometer (TLS), the gas manifolds (MNx), the microvalves $(\mathrm{Vx})$ and high conductance valves $(\mathrm{HCx})$, the hydrocarbon and noble gas trap, the sample manipulation system (SMS) with two solid sample inlet tubes (SSIT-1 and SSIT-2) and two pyrolysis ovens (Oven-1 and Oven-2), the helium gas reservoirs (He-1 and He-2), pressure sensors (PMx), and miniature wide-range pumps (WRP-1 and WRP-2). The manifold and pipe heaters and associated temperature sensors are not shown.

of $50 \pm 8 \mathrm{mg}$ ( $2 \sigma$ standard deviation) per portion delivered to SAM was estimated [Anderson et al., 2012b].

\subsection{SAM Instrument and Operational Modes}

[7] The details of the SAM instrument suite have been described previously [Mahaffy et al., 2012]. Here we focus on two modes of SAM operation that were used in the analyses presented here: (1) evolved gas analysis (EGA) with the quadrupole mass spectrometer (QMS) and (2) the gas chromatograph mass spectrometer (GCMS). Figure 1 shows the gas flow diagram of the SAM instrument indicating the helium flow path used in each mode, and Tables 1 and 2 show the experimental details of the samples analyzed at Rocknest. Prior to both EGA and GCMS analyses, a single quartz glass cup (59 total quartz cups in SAM) sealed inside the pyrolysis oven was heated to $\sim 835^{\circ} \mathrm{C}$, the gas transfer lines and manifolds were heated to $\sim 135^{\circ} \mathrm{C}$, and the hydrocarbon trap to $\sim 300^{\circ} \mathrm{C}$ while being flushed with high purity $(99.999 \%)$ helium to reduce the volatile background in the SAM gas processing system. The background in SAM (i.e., the blank runs) was determined by first simulating a cup sample handoff inside the sample manipulation system (SMS) by removing the preconditioned cup from the pyrolysis oven and then rotating the cup under the solid sample inlet tube (SSIT-1). The empty cup was then sealed inside pyrolysis oven 1 using an oven knife edge to copper ring interface, and volatiles on the cup as well as the volatile background inside the SAM gas processing system were measured as a function of temperature during pyrolysis using EGA only on Sol 86 and both EGA and GCMS modes on Sol 88 under similar conditions that were used for the Rocknest runs (Table 1). The empty cup remained sealed inside the pyrolysis oven after EGA on Sol 86; therefore, no additional SMS cup exposure occurred between runs.

Table 1. Details of the SAM Experiments at Rocknest

\begin{tabular}{lcccccc}
\hline Experiment ID Number & Sample & \multicolumn{1}{c}{ Analysis on Mars } & Cup Number & EGA Pyrolysis Temperature & GC Hydrocarbon Trap Cut & TLS Temperature Cut \\
\hline $25032 / 25033^{\mathrm{d}}$ & Blank & Sol 86/88 & 15 & $30-827^{\circ} \mathrm{C}$ & $146-533^{\circ} \mathrm{C}$ & $548-702^{\circ} \mathrm{C}$ \\
25038 & Rocknest\#1 & Sol 93 & 15 & $30-834^{\circ} \mathrm{C}$ & $146-533^{\circ} \mathrm{C}$ & $548-702^{\circ} \mathrm{C}$ \\
25041 & Rocknest\#2 & Sol 96 & 13 & $32-837^{\circ} \mathrm{C}$ & $98-425^{\circ} \mathrm{C}$ & $440-601^{\circ} \mathrm{C}$ \\
25044 & Rocknest\#3 & Sol 99 & 11 & $31-851^{\circ} \mathrm{C}$ & $533-822^{\circ} \mathrm{C}$ & $234-425^{\circ} \mathrm{C}$ \\
$25048 / 25056^{\mathrm{d}}$ & Rocknest\#4 & Sol 117/171 & 7 & $32-857^{\circ} \mathrm{C}$ & $245-285^{\circ} \mathrm{C}$ & $350-445^{\circ} \mathrm{C}$ \\
\hline
\end{tabular}

${ }^{\mathrm{a}}$ Estimated cup temperature calculated from the SAM pyrolysis oven 1 heater wire temperature data during the $35^{\circ} \mathrm{C} / \mathrm{min}$ ramp using temperature models and a polynomial fit.

${ }^{\mathrm{b}} \mathrm{GC}$ hydrocarbon trap cut refers to the temperature range at which volatiles were collected on the hydrocarbon trap during pyrolysis for GCMS analyses.

${ }^{\mathrm{c}}$ The tunable laser spectrometer (TLS) data from these temperature cuts are not discussed in this paper but are included for completeness.

${ }^{d}$ EGA only and combined EGA-GCMS experiments were run on separate sols with different experiment identification numbers. 
Table 2. SAM and Laboratory Instrument Parameters ${ }^{\mathrm{a}}$

\begin{tabular}{|c|c|c|c|c|c|}
\hline \multirow{2}{*}{$\frac{\text { Instrumentation }}{\text { Location }}$} & \multirow{2}{*}{$\begin{array}{l}\text { SAM FM } \\
\text { Rocknest }\end{array}$} & \multicolumn{2}{|c|}{ Laboratory EGA } & \multicolumn{2}{|c|}{ Laboratory GCMS } \\
\hline & & GSFC & JSC & GSFC & MIT \\
\hline \multicolumn{6}{|c|}{ Pyrolysis oven and transfer lines } \\
\hline Initial $\left({ }^{\circ} \mathrm{C}\right)$ & $\sim 30$ & 50 & 30 & 45 & 50 \\
\hline Final $\left({ }^{\circ} \mathrm{C}\right)$ & $\sim 835$ & 1050 & 720 & 850 & 650 \\
\hline Ramp rate $\left({ }^{\circ} \mathrm{C} / \mathrm{min}\right)$ & 35 & 35 & 35 & 35 & 35 \\
\hline He pressure (mbar) & 25 & 30 & 30 & 1013 & 1013 \\
\hline He flow rate $(\mathrm{sccm})$ & $\sim 0.8^{\mathrm{b}}$ & 0.5 & 0.1 & 23 & 35 \\
\hline Split flow (to MS) & $\sim 800: 1^{\mathrm{b}}$ & $10: 1$ & ND & & \\
\hline Valve oven $\left({ }^{\circ} \mathrm{C}\right)$ & & & & 300 & 300 \\
\hline Transfer line $\left({ }^{\circ} \mathrm{C}\right)$ & 135 & $\begin{array}{c}135 \\
\text { Hydroca }\end{array}$ & 100 & 135 & 300 \\
\hline Initial $\left({ }^{\circ} \mathrm{C}\right)$ & 5 & & & 5 & 50 \\
\hline Final $\left({ }^{\circ} \mathrm{C}\right)$ & 300 & & & 300 & 300 \\
\hline Desorption time (min) & 4 & & & 4 & 5 \\
\hline \multicolumn{6}{|c|}{ Cryo-focuser } \\
\hline Initial $\left({ }^{\circ} \mathrm{C}\right)$ & & & & & -20 \\
\hline Final $\left({ }^{\circ} \mathrm{C}\right)$ & & & & & 300 \\
\hline Desorption time (min) & & & & & 5 \\
\hline \multicolumn{6}{|c|}{ Gas chromatograph $(G C)$} \\
\hline Column type & MXT-CLP & & & MXT-Q-Bond & Rtx-CLP \\
\hline He flow rate $(\mathrm{sccm})$ & $\sim 0.4^{\mathrm{b}}$ & & & 1.5 & 1.5 \\
\hline Split flow (to MS or GC) & $\sim 250: 1^{\mathrm{b}}(\mathrm{MS})$ & & & $10: 1(\mathrm{GC})$ & $10: 1(\mathrm{GC})$ \\
\hline Initial temperature $\left({ }^{\circ} \mathrm{C}\right)$ & 50 & & & 50 & 35 \\
\hline Hold (min) & 4 & & & 4 & 5 \\
\hline Ramp rate $\left({ }^{\circ} \mathrm{C} / \mathrm{min}\right)$ & 10 & & & 10 & 10 \\
\hline Final temperature $\left({ }^{\circ} \mathrm{C}\right)$ & 220 & & & 250 & 300 \\
\hline Final hold (min) & 3 & & & 5 & 8.5 \\
\hline \multicolumn{6}{|c|}{ Quadrupole mass spectrometer (QMS) } \\
\hline Scan range $(m / z)$ & $2-535$ & $2-535$ & $2-300$ & $25-350$ & $10-535$ \\
\hline
\end{tabular}

${ }^{\text {a}}$ SAM flight module (FM) instrument parameters used to analyze the Rocknest materials compared to Mars analog laboratory EGA and pyrolysis GCMS instrument parameters used at the NASA Goddard Space Flight Center (GSFC), the NASA Johnson Space Center (JSC), and the Massachusetts Institute of Technology (MIT). ND= not determined.

${ }^{\mathrm{b}}$ Values based on a model of the SAM gas processing system which considered the Martian ambient pressure, the SAM helium pressure regulator setting, the thermal state of the pipes and manifolds, and SAM valve states to compute time-accurate values for pressure and flow rates within the SAM instrument. The uncertainties in the modeled values are approximately $\pm 15 \%$.

[8] After the empty cup blank runs, individual portions of the Rocknest sample (hereafter, Rocknest\#1-4) from the MSL SA/SPaH portioner were dropped individually into a preconditioned quartz glass cup rotated underneath SSIT-1 by the SMS and then sealed inside SAM pyrolysis oven 1. A helium flow rate of $\sim 0.8$ standard $\mathrm{cm}^{3}$ per minute $(\mathrm{sccm})$ was established to maintain the pressure in the manifold and pyrolysis oven between the flow restrictor out of the helium reservoir (He1) and the flow restrictor associated with valve V20 at approximately 25 mbar. After preheating the quartz cup to $\sim 30^{\circ} \mathrm{C}$ for $15 \mathrm{~min}$, the cup was heated to a temperature of $\sim 835^{\circ} \mathrm{C}$ at a ramp rate of $35^{\circ} \mathrm{C} / \mathrm{min}$ while the QMS was continuously scanned (SAM experimental parameters are shown in Table 2). A small fraction of the gas released during pyrolysis was then ionized by electron impact at $70 \mathrm{eV}$ and mass scanned by the QMS with ions detected via the continuous dynode electron multiplier 2 through flow restrictor 3 at V11 in EGA mode. A model of the SAM gas processing system indicates that approximately one part in 800 (Table 2; split flow $\sim 800: 1)$ of the gas stream directed to the hydrocarbon trap or tunable laser spectrometer (TLS) is diverted into the QMS.

[9] At selected sample temperature intervals in the pyrolysis oven ramp the gas flow was diverted through the SAM hydrocarbon trap (i.e., the gas chromatograph (GC) hydrocarbon trap temperature cut, Table 1). The hydrocarbon trap consists of three adsorbents in series: $0.49 \mathrm{~g}$ of $0.38 \mathrm{~mm}$ nonporous silica beads, $0.079 \mathrm{~g}$ of $60 / 80$ mesh Tenax TA (porous 2,6-diphenylene oxide polymer resin adsorbent), and
$0.11 \mathrm{~g}$ of $60 / 80$ Carbosieve G (graphitized carbon). The hydrocarbon trap was set to an initial temperature of $\sim 5^{\circ} \mathrm{C}$ with thermoelectric coolers prior to exposing the trap to the pyrolysis oven gas flow by opening V46 and V49 (V45 closed). The manifold was then pressurized to $\sim 800$ mbar with helium utilizing V44 from helium tank 1 (Figure 1). After purging GC column 5 (Siltek-treated stainless steel metal-chlorinated pesticides (MXT-CLP), wall coated open tubular (WCOT) polydimethylsiloxane column with phenyl and cyanopropyl stationary phase: $30 \mathrm{~m}$ length, $0.25 \mathrm{~mm}$ internal diameter, $0.25 \mu \mathrm{m}$ film thickness) with helium, the hydrocarbon trap was heated to $\sim 300^{\circ} \mathrm{C}$ for $4 \mathrm{~min}$ under helium flow in the opposite direction of trapping by opening V47 and V48 (V45 closed), and the volatiles released were directed to a smaller injection trap (IT2) containing $0.016 \mathrm{~g}$ of Tenax TA at the front of GC5. Rapid heating of the injection trap marked the start of the GC5 chromatogram set at an initial column temperature of $50^{\circ} \mathrm{C}$ followed by a $10^{\circ} \mathrm{C} / \mathrm{min}$ heating ramp to $220^{\circ} \mathrm{C}$ under a helium flow of $\sim 0.4 \mathrm{sccm}$. Note that for the Rocknest\#4 GCMS analysis the GC conditions were slightly different from the previous runs as follows: $\mathrm{GC}$ initial temperature $30^{\circ} \mathrm{C}, 10^{\circ}$ $\mathrm{C} / \mathrm{min}$ ramp up to $190^{\circ} \mathrm{C}$, helium flow rate $\sim 0.4 \mathrm{sccm}$. Volatiles eluting from GC5 were detected by a thermal conductivity detector (TCD5) and by the QMS on a fraction of gas diverted into the mass spectrometer (split ratio to QMS of $\sim 250: 1$ calculated from a SAM gas flow model). The flow restrictor split design prevents the vacuum of the mass spectrometer with its miniaturized pump (WRP1) from being overloaded with 


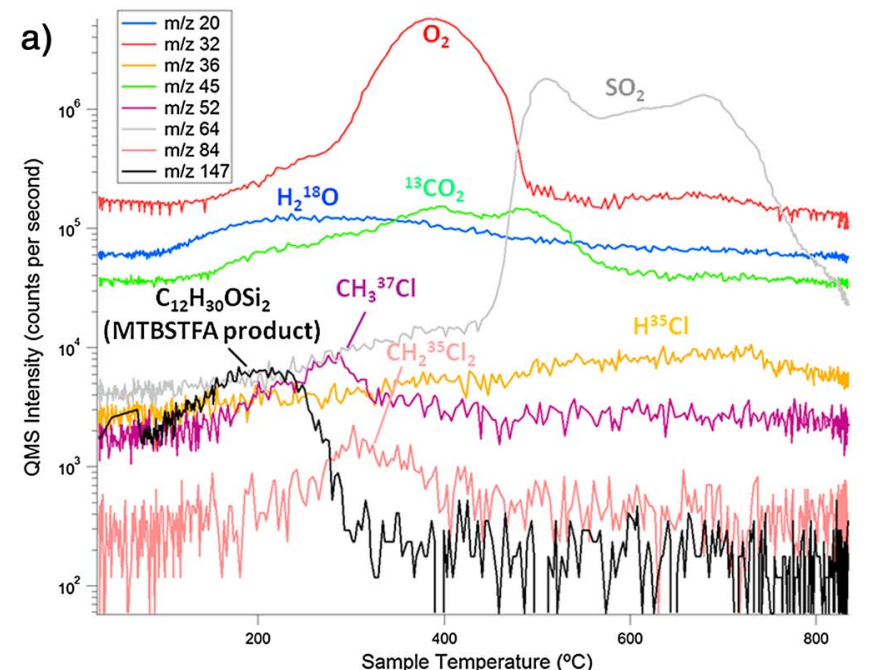

GC (Rocknest\#4)
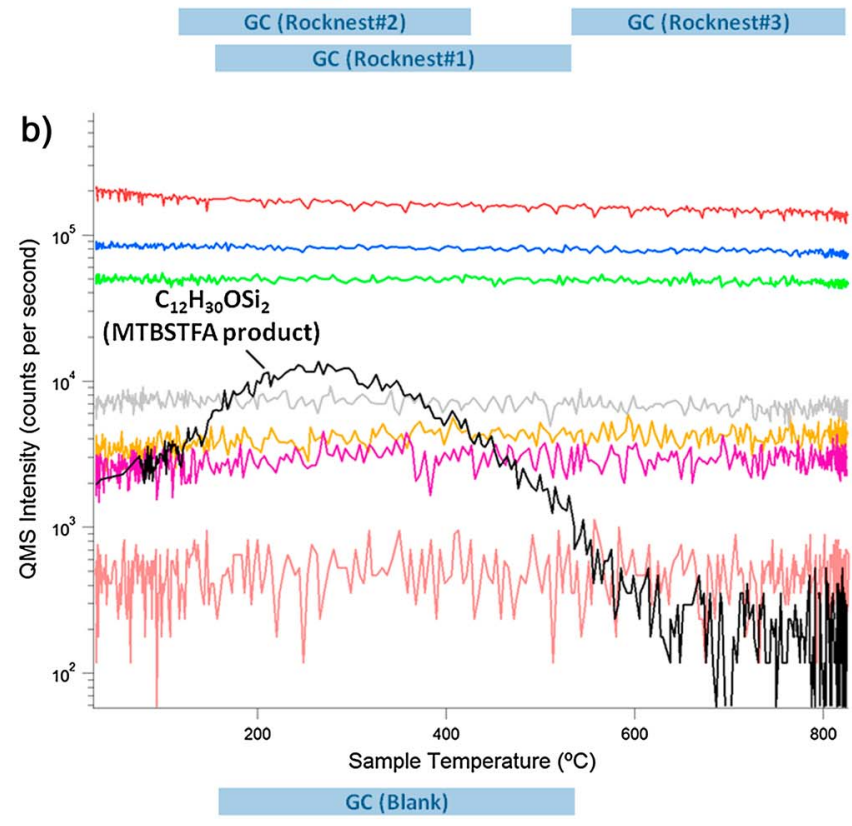

Figure 2. (a) SAM EGA of Rocknest\#1 compared to (b) the EGA blank showing selected $\mathrm{m} / \mathrm{z}$ values plotted in cps as a function of sample temperature during the pyrolysis run. The hydrocarbon trap temperature cuts used for all of the GC analyses are indicated by blue bars.

helium carrier gas while maintaining the required sensitivity for trace organics detection. Eluting compound masses are detected by the QMS using a smart scanning band algorithm that enables the identification of rapidly eluting organic compounds from the GC by comparison of their mass spectra to a National Institute of Standards and Technology (NIST) mass spectral library. A typical sensitivity limit for GCMS analysis based on hydrocarbon gas calibration standards (benzene and hexane) tested on the SAM flight module (FM) was found to be $\sim 10^{-12} \mathrm{~mol}$ [Mahaffy et al., 2012].

\subsection{Supporting Laboratory Instruments}

[10] In order to help interpret the data collected by SAM, several commercial systems were used under "SAM-like" experimental conditions to investigate a variety of different terrestrial Mars analog materials. The experimental conditions of the commercial EGA and pyrolysis GCMS instruments used for this study at NASA Goddard Space Flight Center (GSFC), NASA Johnson Space Center (JSC), and the Massachusetts Institute of Technology (MIT) compared to the SAM flight instrument conditions employed at Rocknest are described in Table 2. The biggest difference between SAM and laboratory pyrolysis GCMS instruments at GSFC and MIT is that the He pressure during pyrolysis was much lower in SAM ( 25 mbar) compared to the laboratory pyrolysis experiments, which were carried out at 1013 mbar (atmospheric pressure). In addition, the helium flow rate during pyrolysis was much higher for the laboratory pyrolysis GCMS instruments (23 or 35 standard cubic centimeters per minute, $\mathrm{sccm})$ compared to SAM $(\sim 0.8 \mathrm{sccm})$. Although the pyrolysis heating rate $\left(35^{\circ} \mathrm{C} / \mathrm{min}\right)$ and maximum temperatures used in the laboratory experiments were similar to SAM (Table 2), the higher helium flow rate and pressure used in the laboratory pyrolysis GCMS experiments could have had an effect on the relative distribution of pyrolysis products observed compared to SAM. The helium pressure and flow rates of the commercial EGA systems used at NASA GSFC and JSC were similar to SAM, although the split flow to the mass spectrometer (MS) used in these laboratory EGA instruments was much higher than SAM in order to increase the quantity of analyte effectively transferred to the MS.

[11] At NASA JSC, a laboratory Setaram Sensys-Evo differential scanning calorimeter coupled to a Stanford Research Systems Universal Gas Analyzer was run at a pressure of $30 \mathrm{mbar} \mathrm{He}$ with a $0.1 \mathrm{sccm}$ flow rate. Gases were evolved from $30^{\circ} \mathrm{C}$ to $720^{\circ} \mathrm{C}$ at a rate of $35^{\circ} \mathrm{C} / \mathrm{min}$. The split ratio to the MS was not determined. Although the MS has a mass range of 2-300 Da, only 10 masses were monitored for the experiments reported here $(m / z 16,18,32,35,36$, 37, 38, 44, 70, and 72). At GSFC, laboratory EGA was performed using a Frontier PY-3030 pyrolyzer attached to an Agilent 7890A gas chromatograph and 5975C inert XL mass spectrometer detector (MSD). The pyrolyzer was initially held at $50^{\circ} \mathrm{C}$ for $5 \mathrm{~min}$ then ramped at $35^{\circ} \mathrm{C} / \mathrm{min}$ to $1050^{\circ} \mathrm{C}$ where it was held for $0.4 \mathrm{~min}$. Inert pyrolysis under 30 mbar of helium generated evolved gases that were split at a ratio of $10: 1$ and carried with $0.5 \mathrm{sccm}$ helium flow through the inlet, EGA capillary tube (Frontier UADTM$2.5 \mathrm{~N}$ ), and transfer line, all held at an isotherm of $135^{\circ} \mathrm{C}$, to the MSD. The MSD scanned a mass range of 2-535 Da.

[12] Pyrolysis GCMS experiments at MIT were performed using a Chemical Data Systems (CDS) Analytical 5250 pyroprobe equipped with an autosampler, hydrocarbon trap, and cryo-focuser. Sample tubes were dropped into the pyrolysis chamber where they were heated from $50^{\circ} \mathrm{C}$ to $650^{\circ} \mathrm{C}$ at $35^{\circ} \mathrm{C} / \mathrm{min}$. The released volatiles were then trapped on a SAM-like metal hydrocarbon trap filled with equal volumes of glass beads, 60/80 Tenax TA, and 60/80 Carbosieve G at $\sim 50^{\circ} \mathrm{C}$ and desorbed for $5 \mathrm{~min}$ at $300^{\circ} \mathrm{C}$. The cryo-focuser operated at $-20^{\circ} \mathrm{C}$ trapped volatiles released during pyrolysis, and they were subsequently desorbed for $5 \mathrm{~min}$ at $300^{\circ}$ C. The valve oven and transfer line were held at $300^{\circ} \mathrm{C}$ throughout the analyses. GCMS analysis was conducted using an Agilent $6890 \mathrm{~N}$ gas chromatograph coupled to a Micromass Autospec-Ultima mass spectrometer. The GC was equipped with an Rtx-CLPesticides column $(30 \mathrm{~m}$ 


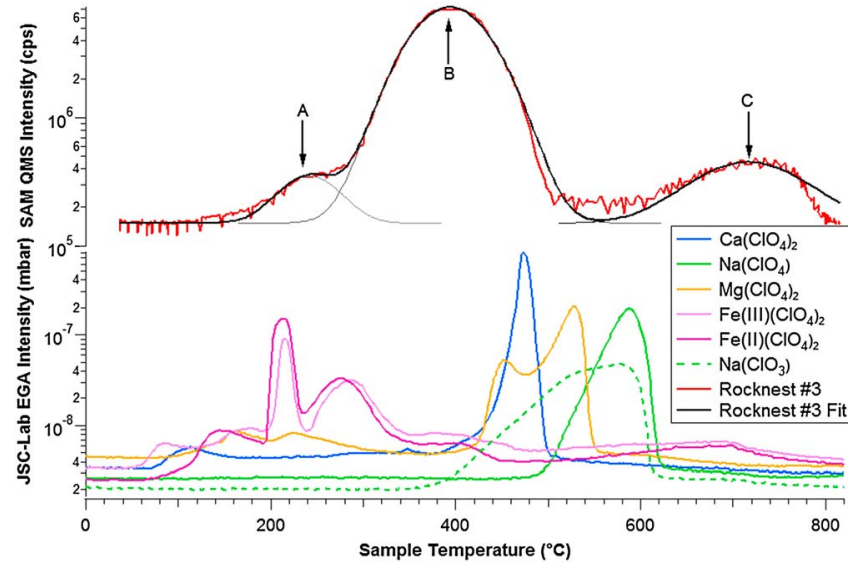

Figure 3. Oxygen release versus sample temperature from the third SAM EGA analysis of Rocknest as measured by SAM compared to select perchlorate and chlorate salts analyzed by the laboratory EGA at JSC. The primary $m / z 32$ peaks evolved from Rocknest\#3 are labeled A-C in the top trace and were fitted to a Gaussian for quantification.

length, $0.25 \mathrm{~mm}$ internal diameter, $0.25 \mu \mathrm{m}$ film thickness) and was operated in split mode with a $10: 1$ split and $1.5 \mathrm{sccm}$ He flow rate. The $\mathrm{GC}$ was held at $35^{\circ} \mathrm{C}$ for $5 \mathrm{~min}$ and then heated to $300^{\circ} \mathrm{C}$ at $10^{\circ} \mathrm{C} / \mathrm{min}$ where it was held for $8 \mathrm{~min}$. The mass spectrometer was operated in electron impact mode at $70 \mathrm{eV}$ and scanned $\mathrm{m} / \mathrm{z} 10-535$ at a rate of $1 \mathrm{~s}$ decade ${ }^{-1}$. Compounds were identified by comparing the resulting mass spectra with a NIST mass spectral library (NIST11). A similar CDS Analytical 5200 pyroprobe was also used at GSFC. The GCMS instrument used at GSFC was a Thermo Finnigan Trace GC equipped with a MXT-Q-Bond (PLOT) column (RESTEK, $30 \mathrm{~m}$ length, $0.25 \mathrm{~mm}$ internal diameter, $8 \mu \mathrm{m}$ film thickness) and Trace DSQII mass spectrometer operating in electron impact mode at $70 \mathrm{eV}$ and scanned $\mathrm{m} / \mathrm{z} 25$ 350 (Table 2). A SAM-like hydrocarbon trap was used during pyrolysis and cooled to $5^{\circ} \mathrm{C}$ during the entire pyrolysis ramp. The MXT-Q-Bond column was used at GSFC rather than the SAM MXT-CLP column to enable better separation of low-molecular-weight volatiles.

\section{SAM Results}

\subsection{SAM Evolved Gas Analysis at Rocknest}

[13] All four Rocknest runs released $\mathrm{H}_{2} \mathrm{O}, \mathrm{CO}_{2}, \mathrm{SO}_{2}$, and $\mathrm{O}_{2}$ well above background levels during EGA in descending order of abundance with water present at approximately 1-2 wt \% assuming a $50 \mathrm{mg}$ sample [Archer Jr. et al., 2013; Leshin et al., 2013]. These volatiles are represented in Figure 2 by the $m / z$ values of the major molecular contributions as follows: $\mathrm{O}_{2}\left(\mathrm{~m} / z\right.$ 32), $\mathrm{SO}_{2}(\mathrm{~m} / z 64), \mathrm{H}_{2} \mathrm{O}(\mathrm{m} / z 20$, primarily $\left.\mathrm{H}_{2}{ }^{18} \mathrm{O}\right)$, and $\mathrm{CO}_{2}\left(\mathrm{~m} / z 45,{ }^{13} \mathrm{CO}_{2}\right)$. The isotopologues of $\mathrm{H}_{2} \mathrm{O}$ and $\mathrm{CO}_{2}$ are plotted since the amounts of $\mathrm{m} / \mathrm{z} 44$ $\left(\mathrm{CO}_{2}\right)$ and $\mathrm{m} / \mathrm{z} 18\left(\mathrm{H}_{2} \mathrm{O}\right)$ saturated the detector in most of the Rocknest runs. The temperatures of release and abundance of $\mathrm{H}_{2} \mathrm{O}$ suggest that this species may be bound to the X-ray amorphous component(s) detected by the CheMin X-Ray Diffraction (XRD) instrument [Bish et al., 2013; Blake et al., 2013]. The $\mathrm{CO}_{2}$ release pattern is likely explained by a combination of sources including combustion of trace amounts of reduced carbon of largely terrestrial origin and decomposition of carbonates [Archer Jr. et al., 2013; Leshin et al., 2013] with carbonate abundances below the $\sim 1 \mathrm{wt} \%$ detection limit of CheMin [Bish et al., 2013; Blake et al., 2013]. $\mathrm{SO}_{2}$, largely evolved at temperatures above $450^{\circ} \mathrm{C}$, reflects thermal decomposition of microcrystalline S-bearing mineral phases, including sulfates, sulfites, or sulfides [Leshin et al., 2013; McAdam et al., 2013].

[14] The broad $\mathrm{O}_{2}$ release from Rocknest at $\sim 350$ to $490^{\circ} \mathrm{C}$ correlates with the release temperatures of the chlorinated hydrocarbons chloromethane and dichloromethane (Figure 2), suggesting the presence of an oxychlorine phase in the Rocknest fines [Leshin et al., 2013]. These gases can all be attributed to thermal degradation of an $\mathrm{O}$ - and $\mathrm{Cl}$-bearing phase such as perchlorate or chlorate, although it should be noted that crystalline perchlorate phases were not detected by CheMin [Bish et al., 2013; Blake et al., 2013]. Therefore, perchlorate in Rocknest may also be part of the $\mathrm{X}$-ray amorphous component or just present at quantities below the $\sim 1 \mathrm{wt} \%$ CheMin detection limit for crystalline perchlorates. Assuming that all of the $\mathrm{O}_{2}$ detected by SAM EGA derives from perchlorate, the estimated abundance of perchlorate anion $\left(\mathrm{ClO}_{4}{ }^{-}\right)$in the Rocknest fines $<150 \mu \mathrm{m}$ fraction is $\sim 0.3$ to $0.5 \mathrm{wt} \%$ [Leshin et al., 2013], which is similar to the abundances of perchlorate anion reported by Phoenix [Hecht et al., 2009]. The abundance of perchlorate measured by SAM does not account for all of the chlorine detected by the Alpha Proton X-ray Spectrometer (APXS) [Blake et al., 2013]; thus, other Cl-bearing phases such as chlorides may be present in Rocknest. The release of $\mathrm{HCl}$ during pyrolysis of Rocknest appears to roughly track the $\mathrm{SO}_{2}$ release at elevated temperatures (Figure 2). Although some of this $\mathrm{HCl}$ could be formed from the reaction of $\mathrm{H}_{2} \mathrm{O}$ with a chloride salt or $\mathrm{Cl}_{2}$ released during perchlorate decomposition in Rocknest, it is also possible that $\mathrm{HCl}$ is forming by a Hargreaves reaction of $\mathrm{SO}_{2}$ with chloride salts to form $\mathrm{HCl}$ and sulfate phase in the presence of water at elevated temperatures.

[15] The $m / z 32$ release from Rocknest\#3 consisted of three separate peaks (peaks A, B, and C), and each peak was fit to a Gaussian curve as shown in Figure 3. Laboratory EGA experiments determined that $\mathrm{O}_{2}$ release temperatures from $\mathrm{Ca}$ perchlorate, Fe perchlorate, $\mathrm{Na}$ perchlorate, $\mathrm{Mg}$ perchlorate, and $\mathrm{Na}$ chlorate under SAM-like conditions do not unequivocally match the $\mathrm{SAM} \mathrm{O}_{2}$ release temperatures (Figure 3, peaks $\mathrm{A}$ and $\mathrm{B}$ ). Nevertheless, $\mathrm{O}_{2}$ release temperatures from calcium perchlorate and the Rocknest materials do overlap making calcium perchlorate $\left(\mathrm{Ca}\left(\mathrm{ClO}_{4}\right)_{2}\right)$ the leading candidate for the main $\mathrm{O}_{2}$ release (Figure 3, peak $\mathrm{B}$ ). Contributions from $\mathrm{Fe}$ perchlorates, super oxide, and/or peroxides [Quinn and Zent, 1999; Yen et al., 2000; Zent and Mckay, 1994; Zent et al., 2008] to the low temperature $\mathrm{O}_{2}$ release centered at $\sim 240^{\circ} \mathrm{C}$ (Figure 3, peak A) are also possible. The high temperature $\left(600-800^{\circ} \mathrm{C}\right) \mathrm{m} / \mathrm{z} 32$ release (Figure 3, peak $\mathrm{C}$ ) corresponds with the $\mathrm{SO}_{2}$ release and is attributed to $\mathrm{SO}_{3}$ from sulfate decomposition that rapidly decomposes into $\mathrm{SO}_{2}$ and $\mathrm{O}_{2}$. Additional chlorate phases have not yet been evaluated (e.g., Ca chlorate, Fe chlorate, and $\mathrm{Mg}$ chlorate) and may yield $\mathrm{O}_{2}$ release temperatures that are more consistent with those measured by SAM. More importantly, laboratory EGA analyses involving mixtures of perchlorates and chlorates with other potential catalytic 


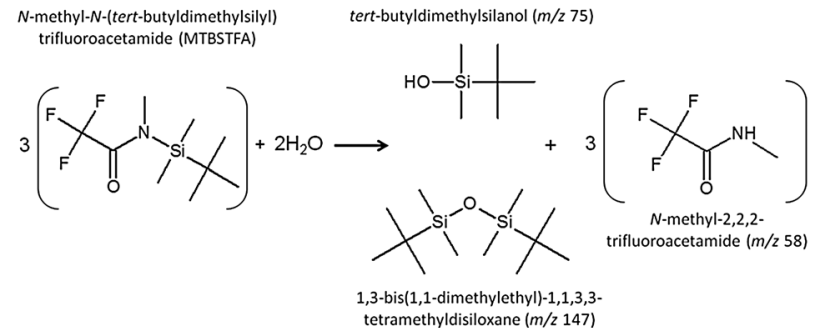

Figure 4. The primary MTBSTFA hydrolysis products and their major mass $(\mathrm{m} / \mathrm{z})$ fragments.

phases may reveal effects on their decomposition temperatures [Furuichi et al., 1974; Markowitz and Boryta, 1965], which could provide a more comprehensive explanation for the broad $\mathrm{O}_{2}$ release characteristics observed by SAM at Rocknest.

[16] It has been previously suggested that metaloperoxides or superoxides in the Martian soil could have been the source of the low temperature $\mathrm{O}_{2}$ released by exposure to water in the Viking Gas Exchange (GEx) experiments [Klein, 1978]. It is also possible that the $\mathrm{O}_{2}$ detected in the Viking GEx experiments was due to release of physically trapped $\mathrm{O}_{2}$ [Nussinov et al., 1978; Plumb et al., 1989; Quinn et al., 2013]. Recently, Quinn et al. [2013] showed that galactic cosmic rays and solar energetic particles can decompose perchlorate in the soil on Mars and result in the formation of hypochlorite or other lower oxidation state oxychlorine species, with a concomitant production of $\mathrm{O}_{2}$ gas that remains trapped in the salt crystal. They suggest that wetting of the soil in the Viking GEx caused the release of this trapped $\mathrm{O}_{2}$. Viking GEx $\mathrm{O}_{2}$ release after exposure of surface samples to water vapor at a temperature of $\sim 25^{\circ} \mathrm{C}$ was between 70 and $770 \mathrm{nmol} \mathrm{O}_{2}$ per $\mathrm{cm}^{3}$ of sample at the VL-1 and VL-2 landing sites [Klein, 1978]. Based on the SAM measured abundance of $\mathrm{O}_{2}$ in the low temperature peak $(\sim 75 \mathrm{nmol})$ released from Rocknest\#3 during pyrolysis (Figure 3, peak A) and assuming a sample volume of $<0.076 \mathrm{~cm}^{3}$, we estimate a minimum low temperature $\mathrm{O}_{2}$ release of $\sim 990 \mathrm{nmol}$ per $\mathrm{cm}^{3}$, similar to the levels of $\mathrm{O}_{2}$ reported by VL-1. The low temperature $\mathrm{O}_{2}$ release seen in Figure 3 may represent the same physical phenomenon as the $\mathrm{O}_{2}$ detected in the Viking GEx experiment.

[17] Several trace chlorinated species including hydrochloric acid $\left(\mathrm{m} / z\right.$ 36: $\left.\mathrm{H}^{35} \mathrm{Cl}\right)$, chloromethane $\left(\mathrm{m} / z\right.$ 52: $\left.\mathrm{CH}_{3}{ }^{37} \mathrm{Cl}\right)$, and dichloromethane $\left(\mathrm{m} / \mathrm{z}\right.$ 84: $\left.\mathrm{CH}_{2}{ }^{35} \mathrm{Cl}_{2}\right)$ were also detected above background in all four SAM EGA analyses of Rocknest (Figure 2a). These trace chlorinated species were not observed in the SAM blank EGA run (Figure 2b), providing additional evidence that these chlorinated compounds are associated with the thermal decomposition of an oxychlorine phase in Rocknest.

[18] One mass fragment that was observed in both the SAM blank and Rocknest EGA runs $(\mathrm{m} / z$ 147) is consistent with a product of one of the SAM wet chemistry reagents, $N$-methyl$N$-(tert-butyldimethylsilyl)trifluoroacetamide (MTBSTFA). This fragment was definitively identified by GCMS as 1,3-bis (1,1-dimethylethyl)-1,1,3,3-tetramethyldisiloxane from its mass spectrum. Another hydrolysis product of MTBSTFA, tert-butyldimethylsilanol, was also identified by GCMS (section 3.3). MTBSTFA is a silylation reagent that can rapidly react with water as well as a wide range of organic compounds with acidic hydrogen atoms including amino acids, carboxylic acids, purines and pyrimidines, primary and secondary amines, alcohols, and amides [Buch et al., 2006; Knapp, 1979; Stalport et al., 2012]. The primary MTBSTFA reaction products with water are shown in Figure 4. Seven of the nine wet chemistry cups inside SAM each contain a mixture of $400 \mu \mathrm{L}(\sim 1.7 \mathrm{mmol})$ MTBSTFA (Sigma-Aldrich, $97 \%$ purity) and $100 \mu \mathrm{L}(\sim 1.3 \mathrm{mmol})$ dimethylformamide (DMF; Pierce, $>99 \%$ purity). These reagents were sealed inside stainless steel foil capped Inconel metal cups by a pinch-off tube prior to loading into the SAM SMS, and all require a mechanical foil puncture prior to first use on Mars [Mahaffy et al., 2012; Stalport et al., 2012]. Since none of the SAM wet chemistry cups were punctured prior to the analyses at Rocknest, some of the MTBSTFA and DMF vapor was likely released inside the SMS through a stressed cup weld or damaged pinch-off tube. It is unknown how much MTBSTFA and DMF vapor were released into the SMS. Any MTBSTFA vapor released could have reacted with water of terrestrial or Martian origin present inside the SMS during sample handoff or water in the gas processing system during the pyrolysis run. Any terrestrial water initially present in SAM would have been exchanged by repeated contact with Martian water during the analyses at Rocknest.

[19] After cup preconditioning, the quartz cup was removed from the pyrolysis oven and exposed to the SMS volatile background during sample delivery from SA/SPaH. Although the vapor pressure of the MTBSTFA/DMF fluid mixture inside the SMS at temperatures of $\sim 0$ to $10^{\circ} \mathrm{C}$ during sample delivery is 5 to 6 orders of magnitude lower than the Mars ambient pressure, it is still possible for trace amounts of this vapor to accumulate on the quartz cups. Based on the area of the $m / z 147$ peak observed in the SAM blank EGA run, $\sim 4 \mathrm{nmol}$ of the primary MTBSTFA hydrolysis product 1,3-bis(1,1-dimethylethyl)-1,1,3,3-tetramethyldisiloxane was estimated to be present on the cup during the pyrolysis of the Rocknest samples. However, SAM GCMS analyses from the same run indicated that a higher amount of 1,3-bis(1,1dimethylethyl)-1,1,3,3-tetramethyldisiloxane $(\sim 16 \mathrm{nmol})$ was present, suggesting that even higher abundances of MTBSTFA may have been present in the SAM gas processing system and available to react with water. Although there was no additional cup exposure to MTBSTFA inside the SMS between the EGA run on Sol 86 and the EGA and GCMS runs on Sol 88 since the cup was kept inside the pyrolysis oven, it is possible that there could have been incomplete removal of MTBSTFA and/or 1,3-bis(1,1-dimethylethyl)-1,1,3,3-tetramethyldisiloxane in the gas processing lines or on the hydrocarbon trap after cup preconditioning prior to the EGA analysis on Sol 86, which could explain the additional 1,3-bis(1,1-dimethylethyl)1,1,3,3-tetramethyldisiloxane measured by GCMS. Another MTBSTFA by-product, $N$-methyl-2,2,2-trifluoroacetamide (TFMA), was also detected in the blank and Rocknest runs; however, the total TFMA abundance estimated from the EGA data ranged from $\sim 0.1$ to $4 \mathrm{nmol}$, which was much lower than the minimum amount of TFMA $(\sim 12 \mathrm{nmol})$ predicted from the reaction of MTBSTFA with water (Figure 4) and the measured amount of 1,3-bis(1,1-dimethylethyl)-1,1,3,3tetramethyldisiloxane and tert-butyldimethyl-silanol observed in the same EGA runs $(\sim 4 \mathrm{nmol})$. Therefore, it is possible that the missing TFMA was oxidized to $\mathrm{CO}_{2}$ and/or decomposed 

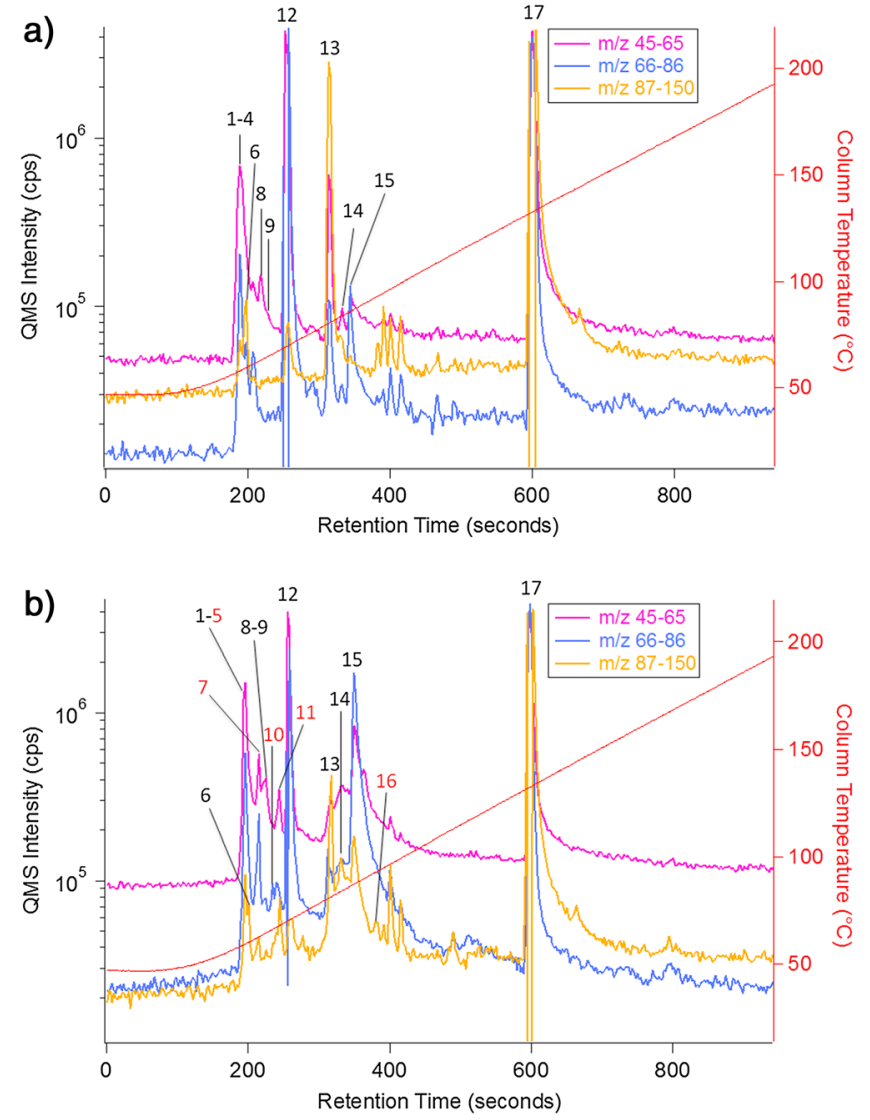

Figure 5. SAM gas chromatograph separation of volatile compounds released during the (a) empty cup blank run and (b) Rocknest\#2. The traces shown represent the intensities of three different band scans over the specified $\mathrm{m} / \mathrm{z}$ ranges in counts per seconds (cps) versus GC retention time after the first injection trap (IT) flash in seconds. Numbered compounds were identified by comparison of their mass spectra to the NIST11 mass spectral library and numbered as indicated in Table 3. The peaks numbered in red (peaks 5, 7, 10,11 , and 16) in the Rocknest\#2 GCMS trace indicate volatiles detected above instrument background levels.

into other products during pyrolysis. However, we were unable to identify specific TFMA decomposition products such as trifluoromethane or trifluoromonochloromethane in the SAM GCMS data. Laboratory pyrolysis GCMS experiments designed to correlate the amount of 1,3-bis(1,1dimethylethyl)-1,1,3,3-tetramethyldisiloxane with the initial amount of MTBSTFA on the cup indicate that the initial quantity of MTBSTFA present on the cup during a pyrolysis run could have ranged from 10 to $\sim 100 \mathrm{nmol}$.

[20] One major difference between the shape and intensity of the 1,3-bis(1,1-dimethylethyl)-1,1,3,3-tetramethyldisiloxane peak observed in the blank compared to the Rocknest runs is the sharp decrease in intensity of the $\mathrm{m} / z 147$ trace as $\mathrm{O}_{2}$ $(\mathrm{m} / \mathrm{z} 32)$ levels begin to rise during pyrolysis of the Rocknest samples at temperatures above $\sim 200^{\circ} \mathrm{C}$ (Figure 2). This indicates that a significant amount of this MTBSTFA by-product is decomposing and/or combusting into $\mathrm{CO}_{2}$ during pyrolysis of the Rocknest samples. The ratio of the area under the $\mathrm{m} / \mathrm{z}$ 147 EGA curve in each Rocknest run to the $m / z 147$ area in the blank, and the assumption that the initial abundance of 1,3-bis(1,1-dimethylethyl)-1,1,3,3-tetramethyldisiloxane on the cup was the same prior to EGA demonstrates that approximately half of this MTBSTFA hydrolysis product decomposed during pyrolysis of the Rocknest samples (\% decomposition: Rocknest\#1, 64\%; Rocknest\#2, 54\%; Rocknest\#3, 61\%; Rocknest\#4, 41\%). If we assume that the maximum amount of MTBSTFA present on the cup was $\sim 100 \mathrm{nmol}$ and a worst case where all of the MTBSTFA carbon was combusted to $\mathrm{CO}_{2}$ during pyrolysis, $\mathrm{CO}_{2}$ derived from $100 \mathrm{nmol}$ MTBSTFA ( $=900 \mathrm{nmol}$ carbon) would contribute a small fraction $(<10 \%)$ of the total $\mathrm{CO}_{2}(\sim 10 \mu \mathrm{mol}$; Leshin et al. [2013]) evolved during the Rocknest EGA experiments. If all of the MTBSTFA carbon was combusted to $\mathrm{CO}_{2}$ consuming $900 \mathrm{nmol}$ of $\mathrm{O}_{2}$, it is possible that the $0.3-0.5 \mathrm{wt} \%$ perchlorate anion abundances determined from $\mathrm{O}_{2}$ production measured by SAM could be underestimated by a maximum of $\sim 20 \%$ based on an average total $\mathrm{O}_{2}$ release of $3.9 \mu \mathrm{mol}$ from Rocknest [Leshin et al., 2013]. However, the SAM EGA results demonstrate that not all of the carbon from the MTBSTFA hydrolysis products are oxidized to $\mathrm{CO}_{2}$. The correlation between the drop in the $\mathrm{m} / \mathrm{z} 147$ signal and the rise of $\mathrm{m} / \mathrm{z} 52$ and $\mathrm{m} / \mathrm{z} 84$ corresponding to the chloromethanes $\mathrm{CH}_{3}{ }^{37} \mathrm{Cl}$ and $\mathrm{CH}_{2}{ }^{35} \mathrm{Cl}_{2}$, respectively (Figure 2), suggest that 1,3-bis(1,1-dimethylethyl)-1,1,3,3-tetramethyldisiloxane is contributing some carbon to these chlorinated hydrocarbons. It should be emphasized that the identification of these trace organic species by their characteristic $\mathrm{m} / \mathrm{z}$ values in EGA mode was only possible after trapping the volatiles on the hydrocarbon trap during pyrolysis (Figure 2) and subsequent GC separation and mass identification by the QMS (section 3.2). In addition, the SAM GCMS mode is more sensitive than EGA and is very useful for the identification and quantification of trace species.

\subsection{SAM Gas Chromatograph Mass Spectrometer Analyses at Rocknest}

[21] Fragments and reaction products associated with MTBSTFA, polysiloxanes derived from the GC column, hydrocarbon trap reaction, and degradation products, as well as other volatiles known to be present in the SAM background were detected in both the blank and Rocknest GCMS analyses (Figure 5). Sources of the SAM background volatiles are discussed in detail elsewhere [Leshin et al., 2013]. The peaks in the GCMS chromatograms in Figure 5 are shown as the QMS intensity (counts per second) of individual bands (band $4=m / z 45-65$; band $5=m / z 66-86$; band $6=m / z$ 87-150) as a function of GC retention time in seconds after the first GC injection trap (IT2) flash heating to $\sim 300^{\circ} \mathrm{C}$. No significant GCMS peak contributions were observed at higher bands corresponding to $\mathrm{m} / \mathrm{z} \quad 151-534$ and therefore were not included in Figure 5.

[22] Several chlorinated hydrocarbons including chloromethane $\left(\mathrm{CH}_{3} \mathrm{Cl}\right)$, dichloromethane $\left(\mathrm{CH}_{2} \mathrm{Cl}_{2}\right)$, trichloromethane (chloroform; $\left.\mathrm{CHCl}_{3}\right)$, a chloromethylpropene $\left(\mathrm{C}_{4} \mathrm{H}_{7} \mathrm{Cl}\right)$, and chlorobenzene $\left(\mathrm{C}_{6} \mathrm{H}_{5} \mathrm{Cl}\right)$ were detected above background levels by GCMS after pyrolysis of the Rocknest samples but were not identified in the blank run (Figure 6). Individual $\mathrm{m} / \mathrm{z}$ values in counts per second (cps) comprising the primary masses of each peak were fitted by Gaussian curves using IGOR Pro 6 (WaveMetrics), and each compound was then uniquely identified by comparison of the mass spectrum generated from the peak fits (shown in red) to the best match found in the 

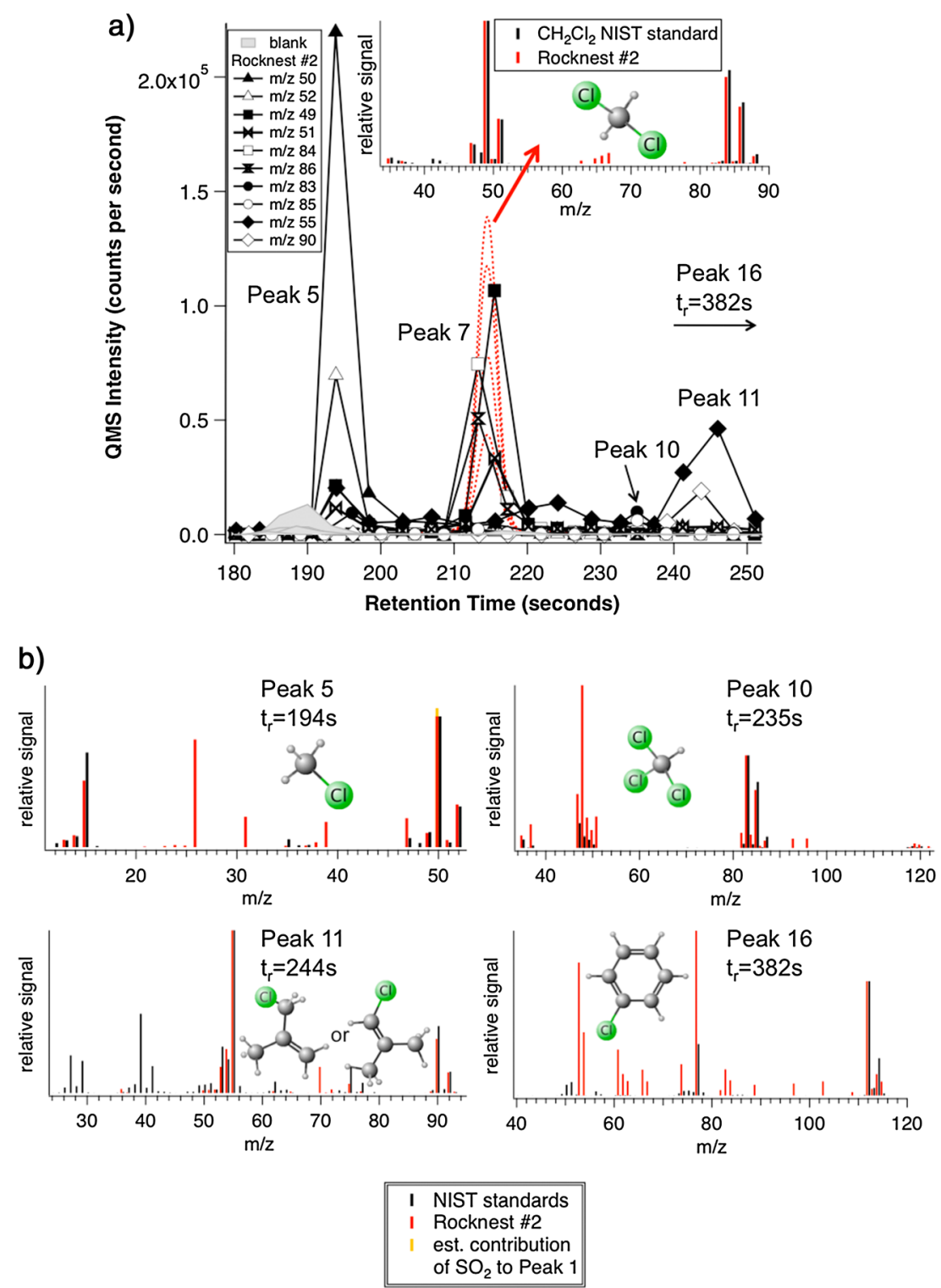

Figure 6. (a) SAM gas chromatogram showing the intensities (in counts per second) of the major masses of the chloromethanes and a chloromethylpropene detected in Rocknest\#2 compared to the blank (shaded peaks) as a function of retention time $\left(\mathrm{t}_{\mathrm{r}}\right)$ in seconds. The mass spectrum for peak 7 compared to the mass spectrum for dichloromethane $\left(\mathrm{CH}_{2} \mathrm{Cl}_{2}\right)$ from NIST is shown in the inset. (b) Mass spectra for the other chlorohydrocarbons identified by SAM compared to NIST reference standards.

NIST11 reference library (Figure 6) and the peaks were numbered as indicted in Table 3 . The total abundance of each identified peak was then estimated by calculating the sum of the areas from selected $\mathrm{m} / \mathrm{z}$ peak fits and comparing the total area to the peak areas from five separate hexane GCMS measurements that were conducted on the SAM instrument during preflight calibration [Mahaffy et al., 2012]. Hexane was used as a standard for the chlorohydrocarbon abundance calculations since this hydrocarbon was not identified in the SAM EGA or GCMS backgrounds and chlorinated hydrocarbon gas standards were not run on the SAM flight instrument during calibration. Differences in the relative molar response of hexane compared to the individual chlorohydrocarbons were accounted for in the abundance calculations using previously published experimental data of their electron ionization cross sections at
70 and $75 \mathrm{eV}$ [Gorocs et al., 2013; Karwasz et al., 1999; Lampe et al., 1957; Makochekanwa et al., 2003]. However, differences in GCMS instrument conditions including injection temperature, GC column type and ramp rate, GC to MS interface and ion source temperatures, and MS tuning can all have an effect on relative molar response (RMR) values [Gorocs et al., 2013]. Therefore, RMR values for these chlorinated hydrocarbons should be established using the SAM testbed instrument at GSFC for more accurate quantification of the SAM flight GCMS abundance data reported in Table 4.

[23] Other volatiles in the GCMS analyses (for example, the $\mathrm{m} / z 50$ fragment of $\mathrm{SO}_{2}$ ) interfere with the detection of chlorinated hydrocarbons. This is caused by the poor GC5 separation, expected on this type of chromatographic column, of several low-molecular-weight nonretained volatiles 
Table 3. Compounds Identified by SAM at Rocknest $\mathrm{t}^{\mathrm{a}}$

\begin{tabular}{lcc}
\hline $\begin{array}{l}\text { Peak } \\
\#\end{array}$ & $\begin{array}{c}\text { Retention } \\
\text { Time (s) }\end{array}$ & Compound Name \\
\hline 1 & 188 & Carbon monoxide \\
2 & 191 & Carbon dioxide \\
3 & 194 & Sulfur dioxide \\
4 & 194 & Formaldehyde \\
5 & 194 & Chloromethane \\
6 & 194 & Hydrogen cyanide \\
7 & 213 & Dichloromethane \\
8 & 224 & Acetone \\
9 & 229 & Acetonitrile \\
10 & 235 & Trichloromethane \\
11 & 244 & Chloromethylpropene \\
12 & 257 & Benzene \\
13 & 317 & Toluene \\
14 & 334 & $N$-Methyl-2,2,2-trifluoroacetamide \\
15 & 346 & Tert-butyldimethylsilanol (MTBSTFA hydrolysis \\
& & product) \\
16 & 382 & Chlorobenzene \\
17 & 598 & 1,3-bis(1,1-dimethylethyl)-1,1,3,3- \\
& & tetramethyldisiloxane (MTBSTFA hydrolysis product)
\end{tabular}

${ }^{\mathrm{a}}$ List of selected peaks identified using the SAM GCMS mode with assigned peak numbers, retention times, and compound identifications by name from the National Institute of Standards and Technology (NIST11) reference library.

shown in Figure 5 (peaks 1-6), and is further evidence for the presence of co-eluting compounds from the mass spectra in Figure 6. Characteristic $m / z$ values in italics in Table 4 and known to have minimal mass interferences from other volatiles present in SAM were therefore used to quantify the chlorinated hydrocarbons. NIST11 relative mass intensities were assumed to determine the areas of the other $\mathrm{m} / \mathrm{z}$ values in Table 4. The reported abundances of the chlorinated hydrocarbons detected by SAM in Table 4 also included an EGA correction factor based on the chloromethane EGA curves to account for the fact that not all of the gas released from the Rocknest samples was sent to the hydrocarbon trap for GCMS analysis. The EGA correction factors used for the Rocknest GCMS runs (Rocknest\#1 =0.94; Rocknest\#2 $=0.77$, Rocknest\#4 $=0.15)$ were determined by dividing the peak area of $m / z 52$ (chloromethane) obtained by integration of a Gaussian fit within the hydrocarbon trap temperature cut range for each Rocknest run (Figure 2a, Table 1) by the total area obtained from the $m / z 52$ peak released over the entire pyrolysis temperature range. It was not possible to calculate EGA correction factors for Rocknest\#3 since there was no $\mathrm{m} / \mathrm{z} 52$ peak observed during the high temperature hydrocarbon trap cut (Figure 2a). The abundances of the chlorinated hydrocarbons detected by SAM GCMS in the Rocknest analyses ranged from $\sim 0.01$ to $2.3 \mathrm{nmol}$ and were all well above background levels (Table 4). Chloromethane was the most abundant chlorinated hydrocarbon detected followed by dichloromethane and 1-chloro-2-methylpropene or its isomer, 3-chloro-2methylpropene. These two chloromethylpropenes could not be uniquely distinguished by SAM since they have the same mass spectrum and may have co-eluted under the GC conditions used. Trichloromethane and chlorobenzene were also detected by SAM but at much lower abundances (Table 4). Upper limits were assigned to peaks that were at background levels or where the mass spectrum did not match the spectrum of the corresponding compound in NIST. Assuming a mass of $50 \mathrm{mg}$ for each Rocknest sample, the concentration of $\mathrm{CH}_{3} \mathrm{Cl}$ and $\mathrm{CH}_{2} \mathrm{Cl}_{2}$ from Rocknest\#1, \#2, and \#4 measured by SAM corresponds to $\sim 0.7$ to 2.3 parts per million (ppm), which is much higher than the 15 parts per billion (ppb) of $\mathrm{CH}_{3} \mathrm{Cl}$ measured by the Viking (VL-1) GCMS instrument [Biemann et al., 1976] and 0.04 to $40 \mathrm{ppb}$ of $\mathrm{CH}_{2} \mathrm{Cl}_{2}$ measured by VL-2 [Biemann et al., 1977]. The Viking GCMS instruments did not carry nor have any MTBSTFA in the backgrounds, so a direct comparison between the SAM and Viking abundances of chlorinated hydrocarbons may not be warranted.

[24] The lower abundances of $\mathrm{CH}_{3} \mathrm{Cl}(0.15 \mathrm{nmol})$ and $\mathrm{CH}_{2} \mathrm{Cl}_{2}(0.02 \mathrm{nmol})$ measured in the Rocknest\#3 run is caused by the GCMS sampling the high temperature pyrolysis cut from the hydrocarbon trap $\left(\sim 533-822^{\circ} \mathrm{C}\right.$, Table 1$)$ at a temperature when most of the $\mathrm{CH}_{3} \mathrm{Cl}$ and $\mathrm{CH}_{2} \mathrm{Cl}_{2}$ had already been vented from the pyrolysis oven and gas lines as indicated by the EGA (Figure 2). The low abundances of chlorinated hydrocarbons in Rocknest\#3 demonstrate that these compounds are effectively purged from the SAM gas processing system between analyses.

[25] Chlorobenzene was not detected in the first blank GCMS run, but this compound was identified above background in all of the Rocknest analyses at abundances ranging from 0.005 to $0.01 \mathrm{nmol}$ (Table 4) as the level of $\mathrm{HCl}$ in SAM increased after pyrolysis of the Rocknest samples. Although estimates of the amount of $\mathrm{HCl}$ released from Rocknest above $300^{\circ} \mathrm{C}$ from the EGA data show that the amount of $\mathrm{HCl}$ increased from $\sim 10 \mathrm{nmol}$ in Rocknest\#1 to $>100 \mathrm{nmol}$ in Rocknest\#4, the levels of chlorobenzene detected by GCMS remained approximately the same. The source of

Table 4. Chlorinated Hydrocarbon Abundances Measured by SAM ${ }^{\mathrm{a}}$

\begin{tabular}{lccccc}
\hline & $\mathrm{CH}_{3} \mathrm{Cl}(\mathrm{nmol})$ & $\mathrm{CH}_{2} \mathrm{Cl}_{2}(\mathrm{nmol})$ & $\mathrm{CHCl}_{3}(\mathrm{nmol})$ & $\mathrm{C}_{4} \mathrm{H}_{7} \mathrm{Cl}(\mathrm{nmol})$ & $\mathrm{C}_{6} \mathrm{H}_{5} \mathrm{Cl}(\mathrm{nmol})$ \\
\hline Blank & $<0.2$ & $<0.006$ & $<0.001$ & $<0.005$ & $<0.001$ \\
Rocknest\#1 & $1.4 \pm 0.5$ & $0.8 \pm 0.3$ & $0.02 \pm 0.01$ & $0.14 \pm 0.05$ & $0.005 \pm 0.002$ \\
Rocknest\#2 & $2.3 \pm 0.8$ & $1.2 \pm 0.5$ & $0.04 \pm 0.02$ & $0.44 \pm 0.16$ & $0.010 \pm 0.004$ \\
Rocknest\#3 & $0.15 \pm 0.06$ & $0.02 \pm 0.01$ & $<0.004$ & $<0.03$ & $0.010 \pm 0.004$ \\
Rocknest\#4 & $2.3 \pm 0.8$ & $0.4 \pm 0.2$ & $0.02 \pm 0.01$ & $0.22 \pm 0.08$ & $0.007 \pm 0.003$ \\
\hline
\end{tabular}

${ }^{\mathrm{a}}$ Calculated abundances $\left(10^{-9} \mathrm{~mol}\right)$ of chloromethane $\left(\mathrm{CH}_{3} \mathrm{Cl}\right)$, dichloromethane $\left(\mathrm{CH}_{2} \mathrm{Cl}_{2}\right)$, trichloromethane $\left(\mathrm{CHCl}_{3}\right)$, chloromethylpropene $\left(\mathrm{C}_{4} \mathrm{H}_{7} \mathrm{Cl}\right)$, and chlorobenzene $\left(\mathrm{C}_{6} \mathrm{H}_{5} \mathrm{Cl}\right)$ measured in the SAM GCMS blank and Rocknest analyses.

In order to minimize $\mathrm{m} / \mathrm{z}$ contributions from other compounds in the GCMS data, the abundances of the chlorinated hydrocarbons were determined from the total peak area calculated from the sum of selected masses determined from a Gaussian fitted peak area of the $m / z$ values in italics listed below and assuming relative $\mathrm{m} / \mathrm{z}$ intensities for the other masses listed determined from NIST. The $\mathrm{m} / \mathrm{z}$ values used for abundance calculations were as follows: $\mathrm{CH}_{3} \mathrm{Cl} \quad(\mathrm{m} / \mathrm{z}=13+15+35+47+49+50+51+52), \quad \mathrm{CH}_{2} \mathrm{Cl}_{2} \quad(\mathrm{~m} / \mathrm{z}=35+41+47+51+84+86+88), \quad \mathrm{CHCl}_{3} \quad(\mathrm{~m} / \mathrm{z}=35+47+82+83+84+85+87)$, $\mathrm{C}_{4} \mathrm{H}_{7} \mathrm{Cl}(\mathrm{m} / \mathrm{z}=27+29+39+41+53+54+55+75+90+92)$, and $\mathrm{C}_{6} \mathrm{H}_{5} \mathrm{Cl}(\mathrm{m} / \mathrm{z}=38,50,51,56,74,75,77,112,113,114)$. Errors $(1 \sigma$ standard deviation $)$ are based on the average value determined from five individual hexane measurements made during preflight calibration of SAM. 
a)

$$
\begin{aligned}
& \text { a) } \mathrm{Ca}\left(\mathrm{ClO}_{4}\right)_{2} \cdot \mathrm{nH}_{2} \mathrm{O} \stackrel{\mathrm{T}<375^{\circ} \mathrm{C}}{\longrightarrow} \mathrm{nH}_{2} \mathrm{O}+\mathrm{Ca}\left(\mathrm{ClO}_{4}\right)_{2} \stackrel{\mathrm{T}>400^{\circ} \mathrm{C}}{\longrightarrow} \mathrm{nH}_{2} \mathrm{O}+\mathrm{CaCl}_{2}+4 \mathrm{O}_{2} \\
& 4 \mathrm{CaCl}_{2}+\mathrm{H}_{2} \mathrm{O} \stackrel{\mathrm{T}>450^{\circ} \mathrm{C}}{\longrightarrow} \mathrm{Ca}_{4} \mathrm{Cl}_{6} \mathrm{O}+2 \mathrm{HCl} \\
& 2 \mathrm{Mg}\left(\mathrm{ClO}_{4}\right)_{2} \cdot \mathrm{nH}_{2} \mathrm{O} \stackrel{\mathrm{T}<350^{\circ} \mathrm{C}}{\longrightarrow} 2 \mathrm{nH}_{2} \mathrm{O}+2 \mathrm{Mg}\left(\mathrm{ClO}_{4}\right)_{2} \stackrel{\mathrm{T}>400^{\circ} \mathrm{C}}{\longrightarrow} 2 \mathrm{nH}_{2} \mathrm{O}+2 \mathrm{MgO}+7 \mathrm{O}_{2}+2 \mathrm{Cl}_{2} \\
& 2 \mathrm{Cl}_{2}+2 \mathrm{H}_{2} \mathrm{O} \longrightarrow 2 \mathrm{HCl}+\mathrm{O}_{2}
\end{aligned}
$$

b)

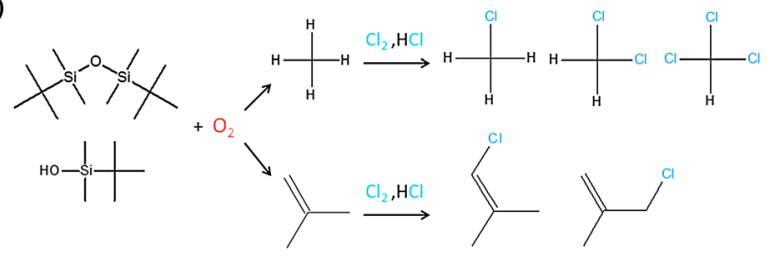

Figure 7. (a) Thermal decomposition of hydrated calcium and magnesium perchlorate at elevated temperatures during SAM pyrolysis would produce $\mathrm{O}_{2}, \mathrm{HCl}$, and $\mathrm{Cl}_{2}$ that could then react with the MTBSTFA hydrolysis products 1,3-bis (1,1-dimethylethyl)-1,1,3,3-tetramethyldisiloxane and tertbutyldimethylsilanol to form the (b) $\mathrm{C}_{1}$-chlorohydrocarbons and $\mathrm{C}_{4}$-chlorohydrocarbons.

the chlorobenzene may be from the reaction of $\mathrm{HCl}$ or $\mathrm{Cl}_{2}$ released during pyrolysis of the Rocknest samples with benzene or toluene on the SAM hydrocarbon trap. Benzene, toluene, and lesser amounts of biphenyl are known products derived from thermal degradation of 2,6-diphenylphenylene oxide (Tenax TA) during heating of the SAM hydrocarbon traps based on preflight calibration and in other laboratory experiments. In addition, the intensities of the benzene and toluene peaks measured by SAM GCMS were similar or higher in the empty cup blank run compared to the Rocknest runs (Figure 5), suggesting a source internal to SAM. Although it has previously been shown that a variety of chlorobenzenes can be formed during pyrolysis of benzoic acid and mellitic acid in the presence of magnesium perchlorate [Steininger et al., 2012], there is no direct evidence from the SAM EGA data that chlorobenzene is being formed from the reaction of reduced carbon with an oxychlorine phase in the Rocknest samples during pyrolysis. Nevertheless, at this time we cannot completely rule out the possibility that trace levels of chlorobenzene below the EGA detection limit are being produced during SAM pyrolysis. A detailed discussion about the origin of the other chlorinated hydrocarbons detected by SAM is presented in the following section.

\subsection{Formation of Chlorinated Hydrocarbons During SAM Pyrolysis}

[26] Chlorinated hydrocarbons are likely being produced from the reaction of Martian chlorine with carbon (primarily terrestrial carbon in SAM) during pyrolysis [Leshin et al., 2013]. The presence of an oxychlorine phase such as calcium perchlorate in Rocknest and the correlation between the evolution of $\mathrm{O}_{2}$ and the production of chloromethane and dichloromethane at temperatures above $200^{\circ} \mathrm{C}$ measured in SAM EGA mode support this conclusion. Nevertheless, there are at least three possible explanations for the source of the chlorinated hydrocarbons identified by SAM acting either individually or together in unknown proportions that must be considered, including (1) reaction of Martian chlorine with Martian organic or Martian inorganic carbon during pyrolysis and/or Martian chlorohydrocarbons in the Rocknest fines, (2) reaction of Martian chlorine with terrestrial organic carbon from the MSL sample handling chain during pyrolysis and/or chlorohydrocarbons present in the sample handling chain, and (3) reaction of Martian chlorine with known terrestrial organic carbon (e.g., MTBSTFA or DMF) in SAM during pyrolysis and/or chlorohydrocarbons present in SAM. It is possible that the primary carbon source for the chlorohydrocarbons detected at Rocknest is from the MTBSTFA present in SAM. However, if Martian organic carbon in Rocknest contributed to the $\mathrm{C}_{1}$-chlorinated and $\mathrm{C}_{4}$ chlorinated hydrocarbons, related $\mathrm{C}_{2}$-chlorohydrocarbons and $\mathrm{C}_{3}$-chlorohydrocarbons might have also been formed, but none were identified by SAM. Nevertheless, a possible Martian carbon contribution to the chloromethanes detected at Rocknest cannot be ruled out, and this possibility is discussed in more detail in section 3.4.

[27] With respect to possibilities (2) and (3) above, the lack of any chlorinated hydrocarbons identified in the SAM blank run $(<0.001$ to $0.2 \mathrm{nmol})$ indicates that the chlorohydrocarbons themselves are not derived from the SAM instrument. This result is not surprising since chlorinated solvents were not used to clean the SAM instrument and gas processing system hardware [Mahaffy et al., 2012]. It is possible that the chlorohydrocarbons were derived from terrestrial contamination in the sample handling chain. However, given that the vapor pressures of chloromethane and dichloromethane are both well above Martian ambient pressure at temperatures above $183 \mathrm{~K}\left(-90^{\circ} \mathrm{C}\right)$ [Ganeff and Jungers, 1948; Hsu and McKetta, 1964] and the temperature of the SA/SPaH Collection and Handling for In situ Martian Rock Analysis (CHIMRA) sample holding cell during the Rocknest analyses ranged from approximately $+20^{\circ} \mathrm{C}$ to $-62^{\circ} \mathrm{C}$, it seems highly unlikely that these chlorohydrocarbons would remain on any hardware surfaces in the sample handling chain. In addition, the CHIMRA subsystem was scrubbed four separate times with Rocknest scooped fines to remove any terrestrial particles from the hardware surfaces prior to the first SAM Rocknest portion delivery from the fifth scoop. CHIMRA swabbed surfaces were also found to be organically clean by laboratory Fourier transform infrared spectroscopy and GCMS measurements prior to launch [Anderson et al., 2012a; Eigenbrode et al., 2013].

[28] The most likely explanation for the source of the chloromethanes and the $\mathrm{C}_{4}$-chlorinated hydrocarbon (1- or 3-chloro-2-methylpropene) identified by SAM is reaction of MTBSTFA in the presence of perchlorate during pyrolysis. This is the preferred explanation because terrestrial MTBSTFA and associated reaction products from the SAM derivatization experiment were identified in both the blank and Rocknest EGA and GCMS analyses (Figures 2 and 5). Moreover, these are the two chlorohydrocarbon classes that would be expected from MTBSTFA degradation in the presence of perchlorate. One possible reaction for the formation of the $\mathrm{C}_{1}$-chlorinated and $\mathrm{C}_{4}$-chlorinated hydrocarbons from the decomposition of calcium and magnesium perchlorate n-hydrates and reaction with the most abundant MTBSTFA hydrolysis products detected in SAM (1,3-bis(1,1-dimethylethyl)-1,1,3,3-tetramethyldisiloxane and tert-butyldimethylsilanol) is shown in Figure 7. Under SAM pyrolysis conditions, both magnesium and calcium perchlorates will dehydrate and decompose into the products shown in the reactions in Figure 7a. 


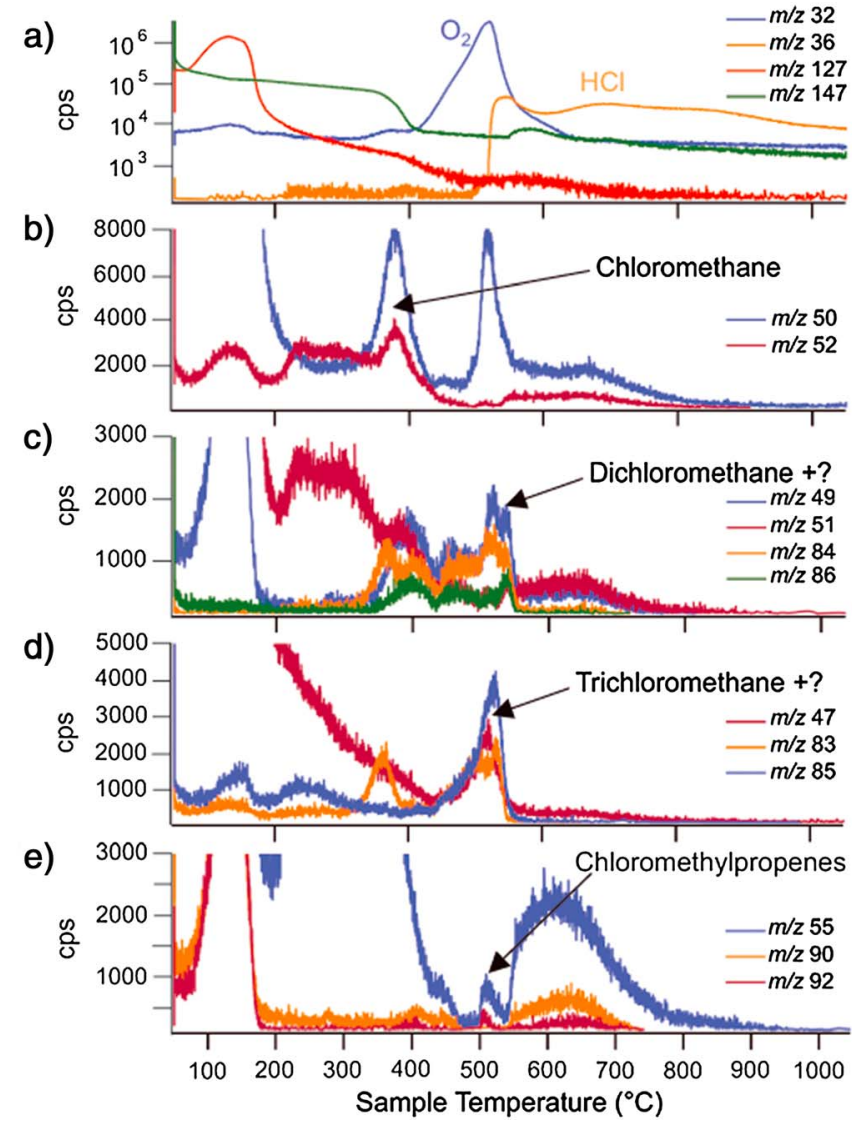

Figure 8. Laboratory EGA of MTBSTFA/DMF (4:1v) and calcium perchlorate $n$-hydrate on inert fused silica. (a) Evolution of MTBSTFA products (represented by $\mathrm{m} / \mathrm{z} 127$ and 147) and calcium perchlorate thermal decomposition products: $\mathrm{O}_{2}(\mathrm{~m} / \mathrm{z} 32)$ and chlorine in the form of $\mathrm{HCl}(\mathrm{m} / \mathrm{z}$ 36) are shown. $\mathrm{Cl}_{2}(\mathrm{~m} / \mathrm{z} 70)$ is not shown but was observed to track the $m / z 36$ pyrogram. (b-e) Key ion pyrograms showing the characteristic $\mathrm{m} / \mathrm{z}$ values of several chlorohydrocarbons are shown. Other products evolving coincidentally with the ions corresponding to dichloromethane and trichloromethane may have a minor influence on the shape of the peaks in these pyrograms. Chlorinated and silylated hydrocarbon products evolved above $\sim 535^{\circ} \mathrm{C}$ indicate incomplete combustion by perchlorate $\mathrm{O}_{2}$ (in Figure 8e).

[29] The details of the thermal decomposition of calcium and magnesium perchlorate as a function of temperature and pressure have been described previously [Acheson and Jacobs, 1970; Cannon et al., 2012; Devlin and Herley, 1986; Migdal-Mikuli and Hetmanczyk, 2008]. The decomposition of these perchlorate salts proceeds in multiple stages with dehydration at temperatures below $375^{\circ} \mathrm{C}$, followed by decomposition of the anhydrous salt at temperatures above $400^{\circ} \mathrm{C}$ [Acheson and Jacobs, 1970; Cannon et al., 2012; Migdal-Mikuli and Hetmanczyk, 2008]. The actual decomposition temperatures of these perchlorates in Rocknest are lower compared to most laboratory experiments since SAM pyrolysis was conducted at a lower pressure of $\sim 25 \mathrm{mbar}$ and other phases in Rocknest could lower the decomposition temperatures of these perchlorates. These perchlorates may contain a significant amount of water under Martian conditions as they are extremely deliquescent and can form eutectic brines down to temperatures as low as -34 to $-74^{\circ} \mathrm{C}$ [Marion et al., 2010; Robertson and Bish, 2011]. Although calcium perchlorate does not produce significant amounts of $\mathrm{HCl}$ or $\mathrm{Cl}_{2}$ during decomposition [Migdal-Mikuli and Hetmanczyk, 2008], formation of some $\mathrm{HCl}$ from the reaction of $\mathrm{CaCl}_{2}$ with $\mathrm{H}_{2} \mathrm{O}$ at elevated temperatures is possible (e.g., Figure 7a; Cannon et al. [2012]). In addition, magnesium perchlorate, if present in Rocknest, would decompose to form $\mathrm{Cl}_{2}$ at elevated temperatures (Figure 7a). Any $\mathrm{Cl}_{2}$ gas released from Rocknest would then rapidly react with $\mathrm{H}_{2} \mathrm{O}$ to form $\mathrm{HCl}$ and $\mathrm{O}_{2}$. Since the chloromethane and dichloromethane release from Rocknest measured by SAM EGA occurred at a lower temperature range of $\sim 200-400^{\circ} \mathrm{C}$ (Figure 2a) compared to the release temperature of $\mathrm{HCl}$ from perchlorate decomposition $\left(\mathrm{T}>400^{\circ} \mathrm{C}\right.$, Figure $7 \mathrm{a}$ ), it is possible that iron oxides or other metal catalysts could have reduced the thermal decomposition temperatures of perchlorates [Furuichi et al., 1974] or other oxychlorine phases in Rocknest.

[30] The formation of the $\mathrm{C}_{1}$-chlorinated hydrocarbons and the $\mathrm{C}_{4}$-chlorinated hydrocarbons (1-chloro-2-methylpropene or its isomer 3-chloro-2-methylpropene) could be the result of $\mathrm{HCl}$ and/or $\mathrm{Cl}_{2}$ reacting with both methane and 2-methylpropene fragments produced from the oxidative decomposition of the MTBSTFA hydrolysis products 1,3-bis (1,1-dimethylethyl)-1,1,3,3-tetramethyldisiloxane or tertbutyldimethylsilanol (Figure 7b). The relative abundances of chloromethane, dichloromethane, and trichloromethane measured by SAM GCMS (Table 4) are consistent with their expected kinetic-based production rates from chlorine gas and methane or methanol [Treger and Rozanov, 1989]. Although the tunable laser spectrometer (TLS) infrared laser was used in the Rocknest experiments for the detection of $\mathrm{CO}_{2}$ and $\mathrm{H}_{2} \mathrm{O}$ and their isotopes [Leshin et al., 2013], the TLS Interband Cascade laser required for methane detection was not in operation. It is possible that trace amounts of $\mathrm{CH}_{4}$ released during the Rocknest pyrolysis experiments are present in the SAM GCMS data; however, definitive identification of $\mathrm{CH}_{4}$ above background was not possible since $\mathrm{CH}_{4}$ cannot be chromatographically separated from other volatile species (e.g., $\mathrm{CO}_{2}, \mathrm{CO}, \mathrm{SO}_{2}, \mathrm{CH}_{2} \mathrm{O}$, and $\mathrm{CH}_{3} \mathrm{Cl}$ ) that elute at the same retention time as $\mathrm{CH}_{4}$ under the $\mathrm{GC}$ conditions employed (Figure 5, peaks 1-5) and also contribute to both $\mathrm{m} / z 15$ and $\mathrm{m} / z 16$ signals needed for $\mathrm{CH}_{4}$ identification. We also searched for methanol $\left(\mathrm{CH}_{3} \mathrm{OH}\right)$ in the SAM GCMS data, but this compound was not detected in the blank or Rocknest analyses. Although there was no direct evidence for the presence of dimethylformamide (DMF) in the SAM EGA or GCMS analyses, this compound is present in the SAM derivatization cups and therefore could provide another carbon source for the formation of the chloromethanes but not the chloromethylpropenes. At a minimum, estimates of the total amount of 1,3-bis(1,1dimethylethyl)-1,1,3,3-tetramethyldisiloxane initially present on the cups $(\sim 4 \mathrm{nmol})$ would have provided a sufficient carbon source $(\sim 48 \mathrm{nmol}$ total carbon) for all of the chlorohydrocarbons identified by SAM at Rocknest (Table 4). To test this hypothesis, laboratory analog EGA and GCMS experiments were conducted at MIT and GSFC.

\subsection{Laboratory Analog Experiments With MTBSTFA and Comparison to SAM}

[31] The evolution of chloromethane and dichloromethane observed in SAM EGA mode is coincident with the 


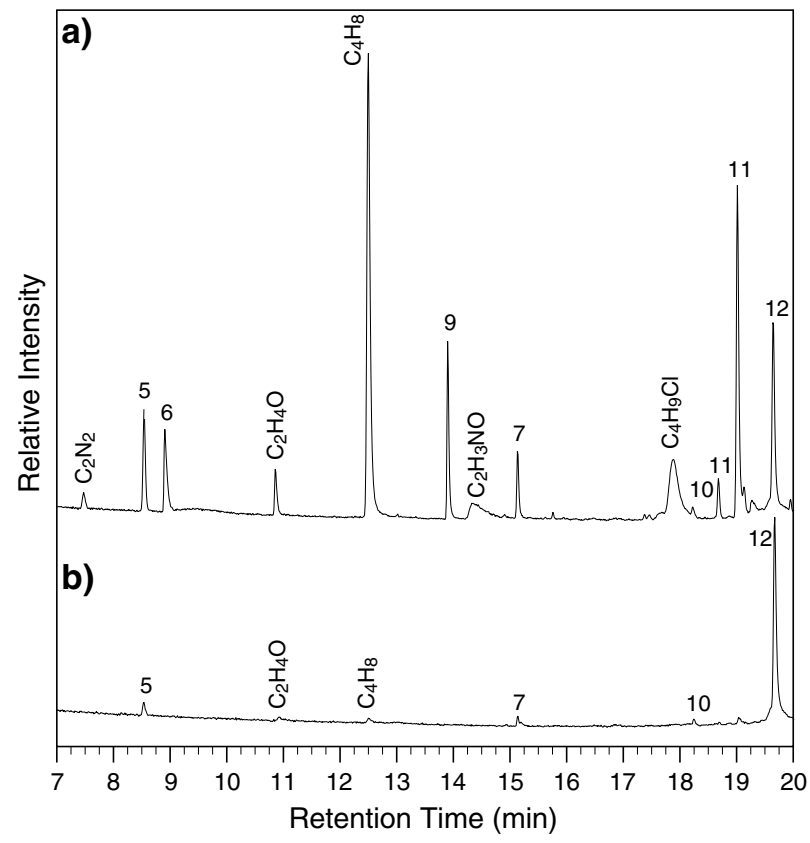

Figure 9. Laboratory GCMS analysis after pyrolysis of (a) $1 \mathrm{wt} \%$ calcium perchlorate tetrahydrate in fused silica with MTBSTFA/DMF compared to (b) $1 \mathrm{wt} \%$ calcium perchlorate tetrahydrate in fused silica with no MTBSTFA or DMF added. The numbered peaks refer to compounds that were also identified by SAM at Rocknest as defined in Table 3. Additional compounds identified in the laboratory pyrolysis GCMS analysis include cyanogen $\left(\mathrm{C}_{2} \mathrm{~N}_{2}\right)$, acetaldehyde $\left(\mathrm{C}_{2} \mathrm{H}_{4} \mathrm{O}\right), \mathrm{C}_{4}$-alkene $\left(\mathrm{C}_{4} \mathrm{H}_{8}\right)$, methyl isocyanate $\left(\mathrm{C}_{2} \mathrm{H}_{3} \mathrm{NO}\right)$, and 2-chloro-2-methylpropane $\left(\mathrm{C}_{4} \mathrm{H}_{9} \mathrm{Cl}\right)$.

beginning of the oxygen release from the Rocknest samples and corresponding decomposition of the hydrolysis product of MTBSTFA $(\mathrm{m} / \mathrm{z}$ 147). To try to reproduce this reaction in the laboratory, FS-120 fused silica (HP Technical Ceramics, Ltd in Sheffield) that was crushed and sieved to $<150 \mu \mathrm{m}$ was then ashed at $550^{\circ} \mathrm{C}$ in air for $3 \mathrm{~h}$ and mixed with $1 \mathrm{wt} \%$ calcium perchlorate tetrahydrate (SigmaAldrich, 99\% purity). The fused silica/calcium perchlorate powder was then spiked with $0.5 \mu \mathrm{L}$ of a $4: 1$ by volume mixture of MTBSTFA:DMF (MTBSTFA: Aldrich >97\% purity; DMF: Sigma-Aldrich, 99.8\% purity) and the entire sample heated to $1050^{\circ} \mathrm{C}$ to evolve gases under SAM-like conditions. The evolution temperature of $\mathrm{O}_{2}\left(\sim 400-600^{\circ} \mathrm{C}\right)$ in this laboratory EGA experiment was slightly higher than observed in the SAM Rocknest EGA runs. Nevertheless, the release of $\mathrm{O}_{2}(\mathrm{~m} / \mathrm{z} 32)$ from the decomposition of the calcium perchlorate that is coincident with the decomposition of 1,3-bis(1,1dimethylethyl)-1,1,3,3-tetramethyldisiloxane $(\mathrm{m} / \mathrm{z} 147)$ and increased levels of $\mathrm{HCl}(\mathrm{m} / \mathrm{z} 36)$ at elevated temperatures (Figure 8a) are all very similar to what was observed by SAM EGA at Rocknest. In addition, $m / z$ peaks corresponding to several chloromethanes and chloromethylpropenes are also observed at temperatures above $350^{\circ} \mathrm{C}$ during the lab EGA analyses (Figures 8b-8e), indicating that these chlorinated hydrocarbons can be produced from the pyrolysis of MTBSTFA and DMF in the presence of calcium perchlorate. One explanation for why trichloromethane and chloromethylpropene were not observed above background in the SAM EGA analyses but were observed in the lab EGA experiments (Figures $8 \mathrm{~d}$ and 8e) is that a much higher split flow to the QMS was used in the lab instrument (10:1) compared to the split flow to the QMS used in the SAM EGA runs $(\sim 800: 1)$. A much larger amount of MTBSTFA $(0.4 \mu \mathrm{L} \sim 1717 \mathrm{nmol})$ was also added to the fused silica/calcium perchlorate sample in the lab experiments compared to the amount of the MTBSTFA hydrolysis product 1,3bis(1,1-dimethylethyl)-1,1,3,3-tetramethyldisiloxane released during SAM EGA ( $\sim \mathrm{nmol})$ or even the worst case estimate of the initial amount of MTBSTFA present on the cup in the SAM analyses $(\sim 100 \mathrm{nmol})$.

[32] Two types of laboratory pyrolysis GCMS experiments using mixtures of both hydrated calcium and magnesium perchlorates and MTBSTFA and DMF were conducted to determine the relative abundances of the $\mathrm{C}_{1}$-chlorinated and $\mathrm{C}_{4}$-chlorinated hydrocarbons produced from MTBSTFA and DMF reactions with perchlorate for comparison to the ratios measured by SAM. The first experiment consisted of packing quartz pyrolysis sample tubes with a quartz filler rod, quartz wool, and $\sim 10 \mathrm{mg}$ of a mineral substrate comprising one of the following: quartz sand, fused silica, or olivine sand. Aqueous solutions of $\mathrm{Mg}\left(\mathrm{ClO}_{4}\right)_{2} \cdot 6 \mathrm{H}_{2} \mathrm{O}$ or $\mathrm{Ca}\left(\mathrm{ClO}_{4}\right)$ ${ }_{2} \cdot 4 \mathrm{H}_{2} \mathrm{O}$ were then added directly to the substrates in each sample tube corresponding to $1 \mathrm{wt} \%$ and allowed to dry at room temperature. A second quartz wool plug was then placed on top of the perchlorate-doped substrate, and $0.6 \mu \mathrm{L}$ MTBSTFA, DMF, or MTBSTFA/DMF (4:1v) was added to the quartz wool immediately prior to analysis in order to minimize evaporation. The second experiment entailed preparing a $1 \mathrm{wt} \% \mathrm{Ca}\left(\mathrm{ClO}_{4}\right)_{2} \cdot 4 \mathrm{H}_{2} \mathrm{O}$ mixture in fused silica with a mortar and pestle. Approximately $20 \mathrm{mg}$ of the fused silica/ calcium perchlorate mixture was added to a quartz sample tube and plugged with quartz wool, and then a $0.5 \mu \mathrm{L}$ mixture of MTBSTFA:DMF (4:1v) was added to the top of the quartz wool so that none of the MTBSTFA/DMF fluid came into contact with the solid sample prior to pyrolysis.

[33] Chloromethane, dichloromethane, trichloromethane, and the $\mathrm{C}_{4}$-chlorohydrocarbons (1- and 3-chloro-2methylpropene) were all identified by GCMS well above background levels after pyrolysis of MTBSTFA and DMF in the presence of calcium perchlorate tetrahydrate (Figure 9a). GCMS peaks corresponding to DMF and the MTBSTFA reaction products $N$-methyl-2,2,2-trifluoroacetamide and tert-butyldimethylsilanol were also identified in this GCMS analysis at later retention times but are not shown because these molecules would dominate the total ion current. Several other MTBSTFA and/or DMF decomposition products including cyanogen $\left(\mathrm{C}_{2} \mathrm{~N}_{2}\right)$, hydrogen cyanide $(\mathrm{HCN})$, acetaldehyde $\left(\mathrm{C}_{2} \mathrm{H}_{4} \mathrm{O}\right)$, a $\mathrm{C}_{4}$-alkene $\left(\mathrm{C}_{4} \mathrm{H}_{8}\right)$, methyl isocynate $\left(\mathrm{C}_{2} \mathrm{H}_{3} \mathrm{NO}\right)$, and 2-chloro-2-methylpropane $\left(\mathrm{C}_{4} \mathrm{H}_{9} \mathrm{Cl}\right)$ were also identified in the samples spiked with MTBSTFA and DMF (Figure 9a). Formaldehyde was also identified by GCMS in the MTBSTFA/DMF and DMF-only perchlorate pyrolysis runs but not in any of the MTBSTFA-only perchlorate pyrolysis runs. The detection of formaldehyde by SAM GCMS at Rocknest (Figure 5) may therefore provide indirect evidence for the presence of trace amounts of DMF that decomposed to formaldehyde during pyrolysis. The lack of DMF detected in the SAM blank EGA and GCMS runs indicates that this compound was not a significant contributor to the chloromethane carbon detected at Rocknest. 
Table 5. $\mathrm{C}_{1} / \mathrm{C}_{4}$-Chlorinated Hydrocarbon Ratios ${ }^{\mathrm{a}}$

\begin{tabular}{|c|c|c|c|c|c|}
\hline \multicolumn{2}{|c|}{ Sample Identification (Instrument/Laboratory) } & \multirow{2}{*}{$\frac{\text { Sum } C_{1} / C_{4}}{-}$} & \multirow{2}{*}{$\frac{\mathrm{CH}_{3} \mathrm{Cl} / \mathrm{C}_{4}}{-}$} & \multirow{2}{*}{$\frac{\mathrm{CH}_{2} \mathrm{Cl}_{2} / \mathrm{C}_{4}}{-}$} & \multirow{2}{*}{$\frac{\mathrm{CHCl}_{3} / \mathrm{C}_{4}}{-}$} \\
\hline Rocknest & Blank (SAM) ${ }^{\mathrm{b}}$ & & & & \\
\hline & Rocknest\#1 (SAM) & 15.9 & 10.0 & 5.71 & 0.14 \\
\hline & Rocknest\#2 (SAM) & 8.05 & 5.23 & 2.73 & 0.09 \\
\hline & Rocknest\#3 (SAM) & $>5.7$ & $>5.0$ & $>0.7$ & - \\
\hline & Rocknest\#4 (SAM) & 12.4 & 10.5 & 1.81 & 0.09 \\
\hline \multirow[t]{8}{*}{ Laboratory analogs } & $1 \mathrm{wt} \% \mathrm{Mg}\left(\mathrm{ClO}_{4}\right)_{2}$ in olivine + MTBSTFA (MIT) & 0.33 & 0.03 & 0.28 & 0.02 \\
\hline & $1 \mathrm{wt} \% \mathrm{Mg}\left(\mathrm{ClO}_{4}\right)_{2}$ in quartz sand + MTBSTFA (MIT) & 0.21 & 0.19 & 0.01 & 0.00 \\
\hline & $1 \mathrm{wt} \% \mathrm{Ca}\left(\mathrm{ClO}_{4}\right)_{2}$ in olivine + MTBSTFA (MIT) & 0.16 & 0.04 & 0.11 & 0.003 \\
\hline & $1 \mathrm{wt} \% \mathrm{Ca}\left(\mathrm{ClO}_{4}\right)_{2}$ in quartz sand + MTBSTFA (MIT) & 0.32 & 0.24 & 0.08 & 0.00 \\
\hline & $1 \mathrm{wt} \% \mathrm{Ca}\left(\mathrm{ClO}_{4}\right)_{2}$ in fused silica + MTBSTFA (MIT) & 0.16 & 0.01 & 0.14 & 0.004 \\
\hline & $1 \mathrm{wt} \% \mathrm{Ca}\left(\mathrm{ClO}_{4}\right)_{2}$ in quartz sand $+\mathrm{DMF}(\mathrm{MIT})^{\mathrm{b}}$ & - & - & - & - \\
\hline & $1 \mathrm{wt} \% \mathrm{Ca}\left(\mathrm{ClO}_{4}\right)_{2}$ in fused silica + MTBSTFA/DMF (MIT) & 0.81 & 0.80 & 0.00 & 0.01 \\
\hline & $1 \mathrm{wt} \% \mathrm{Ca}\left(\mathrm{ClO}_{4}\right)_{2}$ in fused silica + MTBSTFA/DMF (GSFC) ${ }^{\mathrm{c}}$ & 0.35 & 0.25 & 0.05 & 0.05 \\
\hline
\end{tabular}

\footnotetext{
${ }^{\mathrm{a}}$ The $\mathrm{m} / \mathrm{z}$ values used to determine the total peak areas and ratios of the $\mathrm{C}_{1}$-chlorinated and $\mathrm{C}_{4}$-chlorinated hydrocarbons for the $\mathrm{SAM}$ and laboratory analyses were as follows: $\mathrm{CH}_{3} \mathrm{Cl}(\mathrm{m} / \mathrm{z}=13+15+35+47+49+50+51+52), \mathrm{CH}_{2} \mathrm{Cl}_{2}(\mathrm{~m} / \mathrm{z}=35+41+47+51+84+86+88), \mathrm{CHCl}_{3}(\mathrm{~m} / \mathrm{z}=35+47+82+83+84+85+87)$, and $\mathrm{C}_{4} \mathrm{H}_{7} \mathrm{Cl}(\mathrm{m} / \mathrm{z}=27+29+39+41+53+54+55+75+90+92)$.

${ }^{\mathrm{b}}$ Ratios could not be determined since $\mathrm{C}_{4}$-chlorinated hydrocarbons were not identified in these experiments.

${ }^{\mathrm{c}}$ Average values from four separate measurements.
}

[34] Pyrolysis experiment 2 using both magnesium and calcium perchlorate on a variety of different mineral substrates had similar results as pyrolysis experiment 1 . Peak areas and ratios were calculated from the GCMS data by integrating the sum of select $\mathrm{m} / \mathrm{z}$ values (Table 5); these are the same $\mathrm{m} / \mathrm{z}$ values used to calculate the SAM abundances of the $\mathrm{C}_{1}$-chlorinated and $\mathrm{C}_{4}$-chlorinated hydrocarbons observed in the Rocknest samples (Table 4). The relative abundances of the $\mathrm{C}_{1}$-chlorinated to $\mathrm{C}_{4}$-chlorinated hydrocarbons from these experiments ranged from 0.16 to 0.81 (Table 5). This suggests that the $\mathrm{C}_{4}$-chlorinated hydrocarbons are more readily formed from MTBSTFA reacting with perchlorate or are more stable than the $\mathrm{C}_{1}$-chlorinated hydrocarbons under the pyrolysis conditions used. In contrast, the $\mathrm{C}_{1} / \mathrm{C}_{4}$ ratio from the DMF-only experiment was not possible to calculate due to the absence of any detectable $\mathrm{C}_{4}$-chlorinated hydrocarbons in the analysis. The $\mathrm{C}_{1}$-chlorinated hydrocarbons $\mathrm{CH}_{3} \mathrm{Cl}, \mathrm{CH}_{2} \mathrm{Cl}_{2}$, and $\mathrm{CH}_{3} \mathrm{Cl}$, however, were formed as a result of DMF reacting with calcium perchlorate tetrahydrate and/or its decomposition products during pyrolysis. We did not identify any carbon tetrachloride $\left(\mathrm{CCl}_{4}\right)$ above background levels in any of the laboratory pyrolysis GCMS analyses of MTBSTFA and DMF done at GSFC or MIT. This observation is consistent with the lack of any detectable $\mathrm{CCl}_{4}$ by SAM at Rocknest.

[35] The relative molar abundances of the total $\mathrm{C}_{1} / \mathrm{C}_{4}$ chlorinated hydrocarbons measured by SAM at Rocknest $\left(\mathrm{C}_{1} / \mathrm{C}_{4} \sim 6\right.$ to 16$)$ are much higher and more variable than those for the laboratory analog experiments with MTBSTFA and DMF (Table 5). One possibility for this difference is the significantly lower helium flow rate $(\sim 0.8 \mathrm{sccm})$ and pressure ( 25 mbar) used during SAM pyrolysis compared to the laboratory pyrolysis conditions (He flow rate $>23 \mathrm{sccm}$ at atmospheric pressure). Experiments on the SAM flight-like testbed instrument at GSFC will be needed to determine if the helium pressure and flow rate have a significant effect on the $\mathrm{C}_{1} / \mathrm{C}_{4}$ chlorinated hydrocarbon ratio measured by GCMS after pyrolysis of MTBSTFA in the presence of perchlorate. It is also possible that differences in the ratio of MTBSTFA to perchlorate in Rocknest or catalytic effects of the surfaces of the solid particles [Treger and Rozanov, 1989] could change the ratio of $\mathrm{C}_{1} / \mathrm{C}_{4}$ chlorinated hydrocarbons measured by SAM compared to the analogs used in the laboratory analyses.

[36] Another possibility is that the elevated $\mathrm{C}_{1} / \mathrm{C}_{4}$ chlorinated hydrocarbon ratios from Rocknest indicate an additional, as yet unidentified, non-MTBSTFA/DMF organic carbon contribution to the $\mathrm{C}_{1}$-chlorinated hydrocarbons of either terrestrial or Martian origin. For example, some of the chloromethanes in Rocknest could have been produced from the UV or ionizing radiation degradation of meteoritic or Martian organic matter in the presence of chlorine. An inorganic Martian carbon source could also contribute to the formation of the $\mathrm{C}_{1}$-chlorinated hydrocarbons and should be considered. It has been shown experimentally that methane derived from iron and nickel calcium carbonate decomposition [Jagadeesan et al., 2009] can react to form chloromethane and dichloromethane when heated in the presence of magnesium perchlorate [Quinn and Pacheco, 2013]. $\mathrm{CH}_{4}$ could also be produced during SAM pyrolysis of Rocknest from serpentinization reactions involving olivine, water, and $\mathrm{CO}_{2}$ [Oze and Sharma, 2005]. Once produced, the reaction of methane with chlorine in the gas phase and on solids can form all of the $\mathrm{C}_{1}$-chlorinated hydrocarbons [Treger and Rozanov, 1989]. The source of the majority of the evolved $\mathrm{CO}_{2}$ at Rocknest is believed to be derived from the thermal decomposition of $\mathrm{Fe}$ or $\mathrm{Mg}$ carbonates during pyrolysis [Leshin et al., 2013]; therefore, it is possible that methane derived from reactions associated with the decomposition of carbonates in the presence of metal catalysts and perchlorates in Rocknest could have contributed to the chloromethanes. Thus, at this time, while MTBSTFA background in SAM can explain all of the $\mathrm{C}_{1}$ chlorohydrocarbons and $\mathrm{C}_{4}$-chlorohydrocarbons observed, we cannot exclude the possibility that traces of Martianderived carbon contributed to some of the chloromethanes measured by SAM. In subsequent measurements on Mars, SAM will employ a modified pyrolysis program that utilizes an initial low temperature boil-off $\left(\sim 200^{\circ} \mathrm{C}\right.$ for $\left.20 \mathrm{~min}\right)$ to remove the MTBSTFA background from the sample prior to the high temperature pyrolysis ramp. Blank EGA analyses on Mars have demonstrated that this is an effective method for removing MTBSTFA reaction products from the sample. 
Table 6. Chlorine Abundances in Martian Soils ${ }^{\mathrm{a}}$

\begin{tabular}{lcc}
\hline Surface Fines (Detection Method) & Chlorine (wt \%) & References \\
\hline Rocknest soil scoop\#5 (SAM EGA) & $0.3-0.5\left(\mathrm{ClO}_{4}^{-}\right)^{\mathrm{b}}$ & Leshin et al. $[2013]$ \\
Portage scuffed soil (APXS) & 0.61 & Blake et al. $[2013]$ \\
Phoenix soil (WCL) & $0.18-0.25$ & Hecht et al. $[2009]$ \\
Gusev basaltic soils (APXS) & $0.54-0.94$ & Yen et al. $[2006]$ \\
Meridiani basaltic soils (APXS) & $0.41-0.59$ & Yen et al. $[2006]$ \\
Meridiani hematitic soils (APXS) & $0.65-0.77$ & Yen et al. $[2006]$ \\
Pathfinder average soils (APXS) & 0.55 & Bruckner et al. $[2003]$ \\
Viking Lander 1 soil (XRF) & 0.73 (average) & Clark et al. $[1982]$ \\
Viking Lander 2 soil (XRF) & 0.44 (average) Clark et al. $[1982]$ \\
Mars Odyssey (GRS) & 0.49 (average); range $0.1-1$ & Keller et al. $[2006]$ \\
\hline
\end{tabular}

${ }^{a}$ The term Martian soil is used here to denote any loose, unconsolidated materials that can be distinguished from rocks, bedrock, or strongly cohesive sediments. No implication of the presence or absence of organic materials or living matter is intended nor is the genesis of the deposit.

${ }^{b}$ Perchlorate anion abundance calculated from the amount of $\mathrm{O}_{2}$ released from Rocknest and assuming that all of the $\mathrm{O}_{2}$ is derived from perchlorate decomposition.

\section{Discussion}

\subsection{Detection of Chlorinated Hydrocarbons by Viking}

[37] Trace amounts of two simple chlorinated hydrocarbons, chloromethane (VL1 Sample 1, $15 \mathrm{ppb} \mathrm{CH}_{3} \mathrm{Cl}$ ) [Biemann et al., 1976] and dichloromethane (VL2 Sample 1, $\sim 2-14 \mathrm{ppb} \mathrm{CH}_{2} \mathrm{Cl}_{2}$; VL2 Sample 2, $\sim 0.04-40 \mathrm{ppb}$ $\mathrm{CH}_{2} \mathrm{Cl}_{2}$ ) [Biemann et al., 1977] were detected by the Viking GCMS instruments after individual Martian surface samples were heated at temperatures of $200^{\circ} \mathrm{C}, 350^{\circ} \mathrm{C}$, and $500^{\circ} \mathrm{C}$; however, in contrast to other known terrestrial organic contaminants in the Viking GCMS instruments [Biemann et al., 1976; Biemann et al., 1977], these volatile chloromethanes were both absent from the GCMS analyses of the VL1 and VL2 blank runs after heating one of the three ovens up to $500^{\circ} \mathrm{C}$ during cruise [Biemann et al., 1977]. The absence of chloromethane in the VL blank runs was recently attributed to venting to space because so much adsorbed water was expelled from the ovens after heating to $500^{\circ} \mathrm{C}$ that the effluent divider went into a 1:8000 split ratio mode causing the mass spectrometer valve to close [Biemann and Bada, 2011]. The chloromethane and dichloromethane detected in the Viking sample runs were originally thought by Biemann et al. [1977] to be derived from terrestrial sources including cleaning solvents. For example, chloromethane could have been produced from the reaction of adsorbed traces of methanol and $\mathrm{HCl}$ [Laniewski et al., 1998]. In addition, the chloromethane abundance ratio of $\mathrm{m} / \mathrm{z} 50$ to $\mathrm{m} / \mathrm{z} 52$ measured by Viking corresponded to a ${ }^{35} \mathrm{Cl} /{ }^{37} \mathrm{Cl}$ isotope ratio of $\sim 3: 1$ that was similar to the terrestrial chlorine isotope ratio, providing additional support of a terrestrial source of chloromethane [Biemann et al., 1977]. It should be noted that Biemann et al. [1977] did consider the possibility that some of the chloromethane was indigenous to Mars. However, if this were true, Biemann et al. [1977] argued that other related compounds such as ethyl chloride or methyl bromide should also have formed, but none were identified.

\subsection{Global Distribution of Perchlorates on Mars}

[38] The discovery of perchlorate in the Rocknest fines coupled to evidence for perchlorate at the north polar landing site of Phoenix [Hecht et al., 2009] and possibly at the lowmid northern latitude landing sites of VL-1 and VL-2 lends support to the idea of a global distribution of perchlorate in the Martian regolith. Elemental chlorine has been detected at similar levels in every soil analyzed on Mars to date (Table 6), and orbital measurements by the Gamma Ray Spectrometer (GRS) instrument on the Mars Odyssey spacecraft show that chlorine is distributed at similar levels ( $0.49 \mathrm{wt} \%$ average, $0.1-1 \mathrm{wt} \%$ range) from equator to midlatitudes in both hemispheres, with the Tharsis volcanic district and Meridiani regions having the higher abundances [Keller et al., 2006]. The GRS instrument is ineffective for chlorine detection at high latitudes due to interference with water ice. The SNC (Shergottites, Nakhlites, Chassignites) group of meteorites also provide evidence of chlorine in the Martian crust and mantle [Rao et al., 2005]. Whatever formation model is assumed for the perchlorates, these measurements lead to the conclusion that perchlorates are globally distributed on Mars. Though we expect perchlorates to be globally distributed, the abundance of perchlorate anion in Rocknest soil estimated by SAM $\left(\sim 0.3-0.5 \mathrm{wt} \% \mathrm{ClO}_{4}{ }^{-}\right.$, Table 6), assuming that all of the $\mathrm{O}_{2}$ released from Rocknest is due to perchlorate decomposition, cannot account for all of the chlorine detected in the Rocknest scuffed soil by APXS (0.61 wt \%, Table 6), indicating the presence of other chlorine-bearing species in Rocknest or other perchlorates that evolve less $\mathrm{O}_{2}$ than calcium perchlorate (e.g., magnesium perchlorate). The discovery of perchlorates in Rocknest material by SAM adds weight to the argument that both Viking landers measured signatures of perchlorates or other oxychlorine compounds during pyrolysis [NavarroGonzález et al., 2010] in the form of chloromethane and dichloromethane that were detected by the GCMS instruments [Biemann et al., 1976; Biemann et al., 1977]. This is true even if the source of the organic carbon for the chloromethanes detected by Viking was terrestrial in origin [Biemann et al., 1977], since the chlorine could have been Martian. Furthermore, chlorates and chlorites, which can be produced by gamma-irradiated perchlorates, might be the reactive species inferred from the results of the Viking lifedetection experiments. When exposed to similar experimental conditions, chlorates and chlorites produce results very similar to those seen by the Viking labeled release and gas exchange experiments [Quinn et al., 2011].

\subsection{Formation Mechanisms for Perchlorates on Mars}

[39] Two mechanisms for perchlorate production on Mars have been hypothesized. The proposed mechanisms are very similar, the primary difference being that one proposes 
atmospheric formation and the other formation on the surface. The first is an atmospheric process where gas phase oxidation of chlorine by oxygen atoms or ozone produces perchloric acid, with dry deposition followed by surface mineral reactions that results in perchlorates [Catling et al., 2010]. It has been hypothesized that early volcanic activity could have produced high quantities of $\mathrm{HCl}$ where $\mathrm{HCl}$-derived chlorine was later deposited in perchlorate salts by this pathway [Catling et al., 2010]. Although qualitatively correct, this mechanism does not produce sufficient oxides of chlorine in the atmosphere to explain the observed perchlorate abundance [Catling et al., 2010]. Radiation-induced formation of chlorine oxides in the Martian ice [Kim et al., 2013] could mix into the atmosphere and complete the rest of the chemical pathway to perchlorate production. Although it is possible that Martian atmospheric chlorine chemistry was active in the past, ground-based high-resolution infrared spectroscopy measurements of Mars have placed an upper limit of $<0.6 \mathrm{ppb} \mathrm{HCl}$ and $<14.3 \mathrm{ppb}$ $\mathrm{CH}_{3} \mathrm{Cl}$ in the atmosphere, suggesting the lack of an active chlorine chemistry in the present-day Martian atmosphere [Villaneuva et al., 2013]. The second mechanism is formation of perchlorates on the Martian surface by UV photoxidation of chlorides aided by mineral catalysts [Miller et al., 2004; Schuttlefield et al., 2011]. Both of these mechanisms would result in a global distribution of perchlorates on Mars; however, the SAM detection methods at Gale Crater would not distinguish between these two models.

\subsection{Implications of Perchlorate for Future Organic Detection Strategies on Mars}

[40] Although perchlorate is highly stable under Martian conditions, heating perchlorates above their decomposition temperatures will release $\mathrm{O}_{2}$, which can combust some organic materials that might be present in samples. Even in the case of SAM where samples were heated under an inert gas flow of helium, the degradation and partial combustion of nonrefractory terrestrial MTBSTFA to $\mathrm{CO}_{2}$ was observed when the sample was heated above $200^{\circ} \mathrm{C}$. The production of chlorohydrocarbons and $\mathrm{CO}_{2}$ from terrestrial MTBSTFA and potentially other sources of carbon in Rocknest suggests that if there were traces of nonrefractory Martian or exogenous organic material present in Rocknest, that organic carbon might have been oxidized to $\mathrm{CO}_{2}$ or transformed to chlorinated hydrocarbons when heated in the presence of perchlorates as well. It is important to emphasize that not all of the MTBSTFA was destroyed during SAM pyrolysis at Rocknest. In fact, a relatively large fraction $(\sim 44 \%)$ of the MTBSTFA hydrolysis product 1,3-bis(1,1-dimethylethyl)1,1,3,3-tetramethyldisiloxane detected by EGA in Rocknest\#1 survived pyrolysis intact at lower temperatures $\left(<200^{\circ} \mathrm{C}\right)$ prior to the large release of $\mathrm{O}_{2}$ and was detected by GCMS. In addition, organic material that is trapped inside minerals or refractory organic material, such as low $\mathrm{H} / \mathrm{C}$ kerogen that decompose at higher temperatures $\left(>500^{\circ} \mathrm{C}\right)$ and thus would be released as gaseous hydrocarbons after the thermal decomposition of perchlorate and release of $\mathrm{O}_{2}$ was complete, might be entirely decoupled from oxidation in the SAM pyrolysis oven.

[41] Measurements by the Thermal Evolved Gas Analyzer (TEGA) on the Mars Phoenix mission suggested possible combustion of organic material in the presence of a strong oxidizer. The low temperature $\mathrm{CO}_{2}$ release $\left(400-600^{\circ} \mathrm{C}\right)$ detected by TEGA was attributed to adsorbed $\mathrm{CO}_{2}$ contained in a zeolite-type phase, magnesium or iron carbonates, or organic molecules that were converted to $\mathrm{CO}_{2}$ by oxidants (i.e., perchlorate salt) in the soil [Boynton et al., 2009]. Unfortunately, masses corresponding to chlorinated hydrocarbons were not monitored during the TEGA pyrolysis experiments during the Phoenix mission. Subsequent laboratory experiments under TEGA-like operating conditions confirmed the combustion of mellitic acid in the presence magnesium perchlorate [Ming et al., 2009]. A strong exothermic reaction with an onset near $300^{\circ} \mathrm{C}$ was accompanied by $\mathrm{CO}_{2}$ evolution. This exothermic reaction was not present in thermal analyses for samples containing only mellitic acid or only magnesium perchlorate [Lauer et al., 2009]. This strong exothermic reaction is attributed to the combustion of mellitic acid. The combustion is prompted by the release of $\mathrm{O}_{2}$ from the thermal decomposition of the magnesium perchlorate. No organic fragments were detected by the QMS in the evolved gas analysis of the mellitic acid and magnesium perchlorate mixtures. These simple experiments illustrate the probability of organic combustion at elevated temperatures in the presence of strong oxidants, such as perchlorate salts.

[42] Future SAM wet chemistry experiments at sample temperatures below $200^{\circ} \mathrm{C}$ will be carried out to extract and transform polar or refractory organic compounds into more stable volatile derivatives prior to the onset of perchlorate combustion and release of $\mathrm{O}_{2}$. The Mars Organic Molecule Analyzer (MOMA) on the 2018 ExoMars rover mission may avoid the perchlorate oxidation issue by using a laser desorption mode that samples organics directly from solid mineral surfaces [Brinckerhoff et al., 2013]. The extremely brief ( 1 ns) laser pulse desorbs and ionizes organics before they have an opportunity to be degraded and oxidized by the fragments of desorbed perchlorates and other inorganic species. This method has shown significant potential to enable detection and characterization of nonvolatile organics associated with a variety of mineral phases, in the presence of weight percent levels of hydrated calcium and magnesium perchlorates. The analytical potential of laser desorption is further amplified when combined with bulk analysis by pyrolysis GCMS and wet chemistry as also included on MOMA. In addition, the ExoMars rover drill will provide the MOMA instrument with subsurface material down to a maximum depth of $2 \mathrm{~m}$ where organic material would be better protected from ionizing radiation.

\subsection{The Effect of Ionizing Radiation on Organics in the Martian Surface}

[43] The Martian surface regolith could contain several up to $60 \mathrm{ppm}$ organic carbon from meteoritic sources [Steininger et al., 2012]. This estimate assumes a $\sim 2.4 \times 10^{9} \mathrm{~g} / \mathrm{yr}$ constant flux of unmelted micrometeorite carbonaceous material to the Martian surface [Flynn and Mckay, 1990], an average organic carbon content of $\sim 10 \mathrm{wt} \%$ in micrometeorite material [Anders, 1989; Flynn, 1996], a constant micrometeorite influx during Mars' entire history, efficient mixing of a $100 \mathrm{~m}$ regolith, and no degradation of organic material over time caused by radiation or atmospheric derived oxidants. Benner et al. [2000] calculated that benzenecarboxylates derived from the oxidation of meteoritic organic matter on Mars could contribute up to $500 \mathrm{ppm}$ by weight in the top meter of the Martian surface. Analysis of the rover wheel scuff by 
APXS at Rocknest shows that the chemical composition of the soil is similar to the basaltic soils measured by the Mars Exploration Rovers (MER) APXS instruments at Gusev Crater and Meridiani Planum [Blake et al., 2013]. APXS data of the abundance of nickel in the soils measured by MER are consistent with a 1 to $3 \mathrm{wt} \%$ chondritic input to the Martian basaltic soil, which is equivalent to an average meteoritic input of 300 to $1000 \mathrm{ppm}$ organic carbon in the upper few meters of the regolith [Yen et al., 2006]. However, it has been suggested that the nickel enrichments could also come from other sources, such as altered olivine [Newsom et al., 2005]. Therefore, estimates of the chondritic contribution to the Martian soil based on nickel abundances alone should be treated as upper limits. The lack of any definitive evidence of organic carbon of either Martian or meteoritic origins at $\sim$ ppm levels in the Rocknest soil as measured by SAM [Leshin et al., 2013] may indicate either that there is a refractory organic component that is not detectable by SAM pyrolysis GCMS or that degradation of organic material by UV, ionizing radiation, or other chemical oxidation processes in the near-surface has occurred.

[44] Complex organic molecules, if originally present in the small $(<150 \mu \mathrm{m})$ Rocknest fines delivered to SAM, could have been effectively destroyed by UV radiation or atmospheric oxidants while the dust particles were transported by winds in the Martian atmosphere. However, it is not known how long the dust particles were suspended in the air prior to their deposition at the Rocknest location. Trenches created during $\mathrm{SA} / \mathrm{SPaH}$ scooping at Rocknest show that $1-2 \mathrm{~mm}$ sand grains form an armored surface $\sim 2-3 \mathrm{~mm}$ in thickness [Blake et al., 2013]. After deposition and cementation on the surface, organic molecules bound to finer grained particles below the top few millimeters of the Rocknest aeolian deposit should have been shielded from UV radiation, because all UV photons are effectively absorbed in the first millimeter of any exposed rock or soil surface [Cockell and Raven, 2004]. However, even though organic molecules at several centimeters below the surface are well shielded from UV, they can still be altered by ionizing radiation including cosmic rays and their secondary cascade particles. In a recent study, the rate of cosmic ray degradation of organic molecules in the top few meters of a simulated Martian surface regolith was estimated [Pavlov et al., 2012]. Pavlov et al. [2012] found that the abundance of complex organic molecules with molecular masses $>100 \mathrm{Da}$ at a depth of $4-5 \mathrm{~cm}$ below the surface would be decreased by a factor of 1000 in less than 1 billion years of exposure assuming no accumulation of organic material. Pavlov et al. [2012] also show that it would take an even shorter period of time ( $\sim 300$ million years) to destroy organic molecules with masses $>300 \mathrm{Da}$ such as mellitic acid. It should be noted that these calculations are based on radiolysis constants measured for pure dry amino acid mixtures [Kminek and Bada, 2006]. If radiolysis constants determined from amino acid and mineral mixtures are used [Bonner et al., 1985], then the Pavlov et al. [2012] model indicates near complete destruction of organic molecules on timescales of just tens of millions of years.

[45] Conversely, recent analysis of the Antarctic Martian meteorite Roberts Massif (RBT) 04262 showed evidence of low levels of indigenous amino acids in the shergottite [Callahan et al., 2013]. Indigenous reduced organic carbon, including polycyclic aromatic hydrocarbons (PAHs), have also recently been detected in $12 \mathrm{SNC}$ meteorites and confirm previous observations of isotopically light carbon that has been produced by magmatic processes on Mars [Grady et al., 2004; Steele et al., 2012b]. Graphite and a refractory macromolecular carbon phase containing PAHs have also been confirmed to be indigenous to the carbonate globules in the Martian meteorite Allan Hills (ALH) 84001 [Steele et al., 2012a]. The recent measurements contradict previous arguments that the PAHs in the ALH 84001 carbonates are terrestrial in origin [Becker et al., 1997; Stephan et al., 2003] and demonstrate the survival of hydrothermally produced organic compounds over $3.9 \mathrm{Ga}$ on Mars [Jull et al., 1998; McKay et al., 1996; Steele et al., 2012b]. Recent studies of the Tissint meteorite fall have shown the presence of reduced carbon species including organic nitrogen species in this meteorite and in Martian meteorite Northwest Africa 7034 at a level of $\sim 10 \mathrm{ppm}$ [Agee et al., 2013; Steele et al., 2013; Steele et al., 2012b]. The depth of the sample excavated by the impact that liberated all of these meteorites from Mars may have been beyond the range of radiolysis. Furthermore, it is possible that the amino acids in RBT 04262 were synthesized from trapped Martian gases during cooling after the impact via a Fischer-Tropsch-type reaction [Callahan et al., 2013]. The refractory nature of the organics in SNC meteorites may be a result of radiolysis, or it is possible that radiolysis is not as destructive on the surface of Mars as has been modeled previously [Dartnell et al., 2007; Pavlov et al., 2012]. Future measurements by SAM in Gale Crater may help shed additional light on the source, abundance, and distribution of reduced organic carbon compounds on the surface of Mars.

\section{Summary}

[46] The detection of chlorinated hydrocarbons by SAM that were observed during pyrolysis at approximately the same temperature as the rise in $\mathrm{O}_{2}$ released from the Rocknest fines provides strong evidence for the presence of an oxychlorine compound believed to be calcium perchlorate. Although the chlorine from the perchlorate is Martian in origin, the primary carbon source of the chloromethanes and a chloromethylpropene detected by SAM is believed to be terrestrial in origin and derived from a hydrolysis product of $\mathrm{N}$-methyl- $\mathrm{N}$-(tert-butyldimethylsilyl)-trifluoroacetamide (MTBSTFA), a chemical used for derivatization that was present in the SAM background. The detection of these chlorohydrocarbons by GCMS above the $0.001 \mathrm{nmol}$ level demonstrates that the SAM instrument is performing at the designed sensitivity. The high relative abundance of chloromethane and dichloromethane measured by SAM compared to the $\mathrm{C}_{1} / \mathrm{C}_{4}$-chlorinated hydrocarbon ratio measured in laboratory analog experiments may indicate that a non-MTBSTFA carbon source is present. At this time, we cannot rule out the possibility of a Martian carbon contribution to the chloromethanes measured by SAM. Nevertheless, the lack of any definitive evidence for complex organic material of either Martian or meteoritic origins in Rocknest may indicate that a refractory organic component not detectable by pyrolysis GCMS is present in Rocknest or that significant degradation of organic matter by ionizing radiation or other chemical oxidation processes in the Rocknest aeolian deposit has occurred. 
[47] Acknowledgments. NASA provided support for the development of SAM. Data from these SAM experiments will be archived in the Planetary Data System (pds.nasa.gov) in 2013. Essential contributions to the successful operation of SAM on Mars and the acquisition of these data were provided by the SAM development, operations, and testbed teams. D.P.G., J. L.E., K.E.M., M.G.M., J.P.D., and R.E.S. acknowledge funding support from the NASA ROSES MSL Participating Scientist Program. C.F. and P. D.A. acknowledge support from the NASA Postdoctoral Program, administered by Oak Ridge Associated Universities through a contract with NASA We thank M. Benna for providing input on the modeled pressure and flow conditions in SAM. We thank R. Quinn and an anonymous reviewer for helpful comments and appreciate valuable discussions with $\mathrm{H}$. Steininger.

\section{References}

Acheson, R. J., and P. W. M. Jacobs (1970), Thermal decomposition of magnesium perchlorate and of ammonium perchlorate and magnesium perchlorate mixtures, J. Phys. Chem-Us, 74(2), 281-288.

Agee, C. B., et al. (2013), Unique meteorite from early Amazonian Mars: Waterrich basaltic breccia Northwest Africa 7034, Science, 339(6121), 780-785.

Anders, E. (1989), Prebiotic organic matter from comets and asteroids, Nature, 342, 255-257.

Anderson, M. S., I. Katz, M. Petkov, B. Blakkolb, J. Mennella, S. D’Agostino, J. Crisp, J. Evans, J. Feldman, and D. Limonadi (2012a), In situ cleaning of instruments for the sensitive detection of organics on Mars, Rev. Sci. Instrum., 83(10), 105,109.

Anderson, R. C., et al. (2012b), Collecting samples in Gale Crater, Mars; an overview of the Mars Science Laboratory sample acquisition, sample processing and handling system, Space Sci. Rev., 170(1-4), 57-75.

Archer Jr., P. D., et al. (2013), Abundances and implications of volatile-bearing species from evolved gas analysis of the Rocknest aeolian bedform, Gale Crater, Mars, J. Geophys. Res. Planets.

Becker, L., D. P. Glavin, and J. L. Bada (1997), Polycyclic aromatic hydrocarbons (PAHs) in Antarctic Martian meteorites, carbonaceous chondrites, and polar ice, Geochimica Et Cosmochimica Acta, 61(2), 475-481.

Benner, S. A., K. G. Devine, L. N. Matveeva, and D. H. Powell (2000), The missing organic molecules on Mars, Proc. Natl. Acad. Sci. USA, 97(6), 2425-2430.

Biemann, K., and J. L. Bada (2011), Comment on "Reanalysis of the Viking results suggests perchlorate and organics at midlatitudes on Mars" by Rafael Navarro-González et al., J. Geophys. Res., 116, E12001, doi:10.1029/2011JE003869.

Biemann, K., et al. (1976), Search for organic and volatile inorganic-compounds in 2 surface samples from Chryse-Planitia Region of Mars, Science, 194(4260), 72-76.

Biemann, K., et al. (1977), The search for organic substances and inorganic volatile compounds in the surface of Mars, J. Geophys. Res., 82(28), 4641-4658.

Bish, D. L., et al. (2013), X-ray diffraction results from Mars Science Laboratory: Mineralogy of Rocknest aeolian bedform at Gale Crater, Science, 341(6153), doi:10.1126/science.1238932.

Blake, D. F., et al. (2013), Curiosity at Gale Crater, Mars: Characterization and analysis of the Rocknest sand shadow, Science, 341(6153), doi:10.1126/science.1239505.

Bonner, W. A., H. Hall, G. Chow, Y. Liang, and R. M. Lemmon (1985), The radiolysis and radioracemization of amino-acids on clays, Orig. Life Evol. Biosph., 15(2), 103-114.

Boynton, W. V., et al. (2009), Evidence for calcium carbonate at the Mars Phoenix Landing Site, Science, 325(5936), 61-64.

Brinckerhoff, W. B., et al. (2013), Mars Organic Molecule Analyzer (MOMA) Mass Spectrometer for ExoMars 2018 and Beyond, paper presented at IEEE Aerospace Conference.

Bruckner, J., G. Dreibus, R. Rieder, and H. Wanke (2003), Refined data of Alpha Proton X-ray Spectrometer analyses of soils and rocks at the Mars Pathfinder site: Implications for surface chemistry, J. Geophys. Res., 108(E12), 8094, doi:10.1029/2003JE002060.

Buch, A., D. P. Glavin, R. Sternberg, C. Szopa, C. Rodier, R. Navarro-González, F. Raulin, M. Cabane, and P. R. Mahaffy (2006), A new extraction technique for in situ analyses of amino and carboxylic acids on Mars by gas chromatography mass spectrometry, Planet. Space Sci., 54(15), 1592-1599.

Callahan, M. P., A. S. Burton, J. E. Elsila, E. M. Baker, K. E. Smith, D. P. Glavin, and J. P. Dworkin (2013), A search for amino acids and nucleobases in the Martian meteorite Roberts Massif 04262 using liquid chromatography-mass spectrometry, Meteoritics Planet. Sci., 48(5), 786-795.

Cannon, K. M., B. Sutter, D. W. Ming, W. V. Boynton, and R. Quinn (2012), Perchlorate induced low temperature carbonate decomposition in the Mars Phoenix Thermal and Evolved Gas Analyzer (TEGA), Geophys. Res. Lett., 39, L13203, doi:10.1029/2012GL051952.
Catling, D. C., M. W. Claire, K. J. Zahnle, R. C. Quinn, B. C. Clark, M. H. Hecht, and S. Kounaves (2010), Atmospheric origins of perchlorate on Mars and in the Atacama, J. Geophys. Res., 115, E00E11, doi:10.1029/ 2009JE003425.

Chun, S. F. S., K. D. Pang, J. A. Cutts, and J. M. Ajello (1978), Photocatalytic oxidation of organic-compounds on Mars, Nature, 274(5674), 875-876.

Clark, B. C., A. K. Baird, R. J. Weldon, D. M. Tsusaki, L. Schnabel, and M. P. Candelaria (1982), Chemical-composition of Martian fines, J. Geophys. Res., 87(Nb12), 59-67.

Cockell, C. S., and J. A. Raven (2004), Zones of photosynthetic potential on Mars and the early Earth, Icarus, 169(2), 300-310.

Dartnell, L. R., L. Desorgher, J. M. Ward, and A. J. Coates (2007), Martian sub-surface ionising radiation: Biosignatures and geology, Biogeosciences, 4(4), 545-558.

Devlin, D. J., and P. J. Herley (1986), Thermal-decomposition and dehydration of magnesium perchlorate hexahydrate, Thermochim. Acta, 104, 159-178.

Eigenbrode, J. L., et al. (2013), Fluorocarbon contamination from the drill on the Mars Science Laboratory: Potential science impact on detecting Martian organics by Sample Analysis at Mars (SAM), in Lunar Planet. Sci XLIV, edited, Abstract \#1652.

Encrenaz, T., B. Bezard, T. K. Greathouse, M. J. Richter, J. H. Lacy, S. K. Atreya, A. S. Wong, S. Lebonnois, F. Lefevre, and F. Forget (2004), Hydrogen peroxide on Mars: Evidence for spatial and seasonal variations, Icarus, $170(2)$, 424-429.

Ericksen, G. E. (1983), The Chilean nitrate deposits, Am. Sci., 71(4), 366-374.

Flynn, G. J. (1996), The delivery of organic matter from asteroids and comets to the early surface of Mars, Earth Moon Planets, 72(1-3), 469-474.

McAdam, A. C., et al. (2013), Evidence for sulfur-bearing phases in Martian soil fines from SAM volatile analyses at Rocknest, J. Geophys. Res. Planets.

Flynn, G. J., and D. S. Mckay (1990), An assessment of the meteoritic contribution to the Martian soil, J. Geophys. Res., 95(B9), 14,497-14,509.

Furuichi, R., T. Ishii, and K. Kobayash (1974), Phenomenological study of catalytic thermal-decomposition of potassium perchlorate by iron(II) oxides with different preparing histories, J. Therm. Anal., 6(3), 305-320. Ganeff, J. M., and J. C. Jungers (1948), Tensions de Vapeur du Systeme $\mathrm{CH}_{3} \mathrm{Cl}-\mathrm{CH}_{2} \mathrm{Cl}_{2}$, Bull. Soc. Chim. Belg., 57, 82-87.

Gorocs, N., D. Mudri, J. Matyasi, and J. Balla (2013), The determination of GC-MS relative molar responses of some n-alkanes and their halogenated analogs, J. Chromatogr. Sci., 51(2), 138-145.

Grady, M. M., A. B. Verchovsky, and I. P. Wright (2004), Magmatic carbon in Martian meteorites: Attempts to constrain the carbon cycle on Mars, Int. J. Astrobiol., 3, 117-124.

Grotzinger, J. P., et al. (2012), Mars Science Laboratory Mission and Science Investigation, Space Sci. Rev., 170(1-4), 5-56.

Hecht, M. H., et al. (2009), Detection of perchlorate and the soluble chemistry of Martian soil at the Phoenix Lander Site, Science, 325(5936), 64-67.

Hsu, C. C., and J. J. McKetta (1964), Pressure-volume-temperature properties of methyl chloride, J. Chem. Eng. Data, 9(1), 45-51.

Jagadeesan, D., M. Eswaramoorthy, and C. N. R. Rao (2009), Investigations of the conversion of inorganic carbonates to methane, Chemsuschem, 2(9), $878-882$.

Jull, A. J. T., C. Courtney, D. A. Jeffrey, and J. W. Beck (1998), Isotopic evidence for a terrestrial source of organic compounds found in Martian meteorites Allan Hills 84001 and Elephant Moraine 79001, Science, 279(5349), 366-369.

Karwasz, G. P., R. S. Brusa, A. Piazza, and A. Zecca (1999), Total cross sections for electron scattering on chloromethanes: Formulation of the additivity rule, Phys. Rev. A, 59(2), 1341-1347.

ten Kate, I. L., J. R. C. Garry, Z. Peeters, R. Quinn, B. Foing, and P. Ehrenfreund (2005), Amino acid photostability on the Martian surface, Meteorit. Planet. Sci., 40(8), 1185-1193.

Keller, J. M., et al. (2006), Equatorial and midlatitude distribution of chlorine measured by Mars Odyssey GRS, J. Geophys. Res., 111, E03S08, doi:10.1029/2006JE002679.

Kim, Y. S., Y. K. Wo, S. Maity, S. K. Atreya, and R. I. Kaiser (2013), Radiation-induced formation of chlorine oxides and their potential role in the origin of Martian perchlorates, J. Am. Chem. Soc., doi:10.1021/ ja3122922.

Klein, H. P. (1978), Viking biological experiments on Mars, Icarus, 34(3), 666-674

Klein, H. P., J. Lederber, and A. Rich (1972), Biological experimentsViking Mars Lander, Icarus, 16(1), 139-146.

Kminek, G., and J. L. Bada (2006), The effect of ionizing radiation on the preservation of amino acids on Mars, Earth Planet. Sci. Lett., 245(1-2), 1-5.

Knapp, D. R. (1979), Handbook of Analytical Derivatization Reactions, John Wiley \& Sons, Inc., New York, pp. 768. 
Lampe, F. W., J. L. Franklin, and F. H. Field (1957), Cross sections for ionization by electrons, J. Am. Chem. Soc., 79(23), 6129-6132.

Laniewski, K., H. Boren, A. Grimvall, and M. Ekelund (1998), Pyrolysis gas chromatography of chloroorganic compounds in precipitation, J. Chrom. A, 826(2), 201-210.

Lauer, H. V., D. W. Ming, B. Sutter, D. C. Golden, R. V. Morris, and W. V. Boynton (2009), Thermal and Evolved Gas Analysis of Magnesium Perchlorate: Implications for Perchlorates in Soils at the Mars Phoenix Landing Site, paper presented at Lunar Planet. Sci XL, Abstract \#2196.

Leshin, L. A., et al. (2013), Volatile, Isotope and Organic Analysis of Martian Fines with the Mars Curiosity Rover, Science, 341(6153), doi:10.1126/ science. 1238937

Mahaffy, P. R., et al. (2012), The Sample Analysis at Mars investigation and instrument suite, Space Sci. Rev., 170(1-4), 401-478.

Makochekanwa, C., O. Sueoka, and M. Kimura (2003), A comparative study of electron and positron scattering from chlorobenzene $(\mathrm{C} 6 \mathrm{H} 5 \mathrm{Cl})$ and chloropentafluorobenzene (C6F5Cl) molecules, J. Chem. Phys., 119(23), $12,257-12,263$.

Marion, G. M., D. C. Catling, K. J. Zahnle, and M. W. Claire (2010), Modeling aqueous perchlorate chemistries with applications to Mars, Icarus, 207(2), 675-685.

Markowitz, M. M., and D. A. Boryta (1965), The differential thermal analysis of perchlorates. VII. Catalytic decompositions of alkali metal perchlorates by manganese dioxide, J. Phys. Chem-Us, 69(4), 1114.

McKay, D. S., E. K. Gibson, K. L. Thomas-Keprta, H. Vali, C. S. Romanek, S. J. Clemett, X. D. F. Chillier, C. R. Maechling, and R. N. Zare (1996), Search for past life on Mars: Possible relic biogenic activity in Martian meteorite ALH84001, Science, 273, 924-930.

Migdal-Mikuli, A., and J. Hetmanczyk (2008), Thermal behavior of [Ca $(\mathrm{H} 2 \mathrm{O})(4)](\mathrm{ClO} 4)(2)$ and $[\mathrm{Ca}(\mathrm{NH} 3)(6)](\mathrm{ClO} 4)(2), J$. Therm. Anal. Calorim., 91(2), 529-534

Miller, G., R. Kempley, G. Awadh, and K. Richman (2004), Photo-oxidation of chloride to perchlorate in the presence of titanium dioxide and nitrate, Abstr. Pap. Am. Chem S, 228, U92-U92.

Ming, D. W., H. V. Lauer, P. D. Archer, B. Sutter, D. C. Golden, R. V. Morris, P. B. Niles, and W. V. Boynton (2009), Combustion of Organic Molecules by the Thermal Decomposition of Perchlorate Salts: Implications for Organics at the Mars Phoenix Scout Landing Site, paper presented at Lunar Planet. Sci XL, Abstract \#2241.

Moores, J. E., and A. C. Schuerger (2012), UV degradation of accreted organics on Mars: IDP longevity, surface reservoir of organics, and relevance to the detection of methane in the atmosphere, J. Geophys. Res., 117, E08008, doi:10.1029/2012JE004060.

Navarro-González, R., and C. P. Mckay (2011), Reply to comment by Biemann and Bada on "Reanalysis of the Viking results suggests perchlorate and organics at midlatitudes on Mars", J. Geophys. Res., 116, E12002, doi:10.1029/2011JE003880.

Navarro-González, R., E. Vargas, J. de la Rosa, A. C. Raga, and C. P. McKay (2010), Reanalysis of the Viking results suggests perchlorate and organics at midlatitudes on Mars, J. Geophys. Res., 115, E12010, doi:10.1029/2010JE003599.

Newsom, H. E., M. J. Nelson, C. K. Shearer, and D. S. Draper (2005), The Martian Soil as a Geochemical Sink for Hydrothermally Altered Crustal Rocks and Mobile Elements: Implications of Early MER Results, paper presented at Lunar Planet. Sci XXXVI, Abstract \#1142.

Nussinov, M. D., Y. B. Chernyak, and J. L. Ettinger (1978), Model of finegrain component of Martian soil based on Viking Lander data, Nature, 274(5674), 859-861.

Oró, J., and G. Holzer (1979), The photolytic degradation and oxidation of organic compounds under simulated Martian conditions, J. Mol. Evol., 14, $153-160$.

Oyama, V. I., B. J. Berdahl, and G. C. Carle (1977), Preliminary findings of Viking gas-exchange experiment and a model for Martian surface-chemistry, Nature, 265(5590), 110-114.

Oze, C., and M. Sharma (2005), Have olivine, will gas: Serpentinization and the abiogenic production of methane on Mars, Geophys. Res. Lett., 32, L10203, doi:10.1029/2005GL022691.

Pavlov, A. A., G. Vasilyev, V. M. Ostryakov, A. K. Pavlov, and P. Mahaffy (2012), Degradation of the organic molecules in the shallow subsurface of
Mars due to irradiation by cosmic rays, Geophys. Res. Lett., 39, doi:10.1029/2012GL052166.

Plumb, R. C., R. Tantayanon, M. Libby, and W. W. Xu (1989), Chemicalmodel for Viking biology experiments-Implications for the composition of the Martian regolith, Nature, 338(6217), 633-635.

Quinn, R. C., and D. J. Pacheco (2013), Production of Chlorinated Hydrocarbons During the Thermal Decomposition of Metal Carbonates and Perchlorate Salts, paper presented at Lunar Planet. Sci XLIV, Abstract \#2664.

Quinn, R. C., and A. P. Zent (1999), Peroxide-modified titanium dioxide: A chemical analog of putative Martian soil oxidants, Orig. Life Evol. Biosph., 29(1), 59-72.

Quinn, R. C., P. J. Grunthaner, C. L. Taylor, C. E. Bryson, and F. J. Grunthaner (2011), The Radiolytic Decomposition of Soil Perchlorates on Mars, paper presented at Lunar Planet. Sci XLII, Abstract \#2003.

Quinn, R. C., H. F. H. Martucci, S. R. Miller, C. E. Bryson, F. J. Grunthaner, and P. J. Grunthaner (2013), Perchlorate radiolysis on Mars and the origin of the Martian soil reactivity, Astrobiology, 13(6), 515-520.

Rao, M. N., S. R. Sutton, D. S. McKay, and G. Dreibus (2005), Clues to Martian brines based on halogens in salts from nakhlites and MER samples, J. Geophys. Res., 110, E12S06, doi:10.1029/2005JE002470.

Robertson, K., and D. Bish (2011), Stability of phases in the $\mathrm{Mg}(\mathrm{ClO} 4)(2)$ center dot $\mathrm{nH}(2) \mathrm{O}$ system and implications for perchlorate occurrences on Mars, J. Geophys. Res., 116, E07006, doi:10.1029/2010JE003754.

Schuttlefield, J. D., J. B. Sambur, M. Gelwicks, C. M. Eggleston, and B. A. Parkinson (2011), Photooxidation of chloride by oxide minerals: Implications for perchlorate on Mars, J. Am. Chem. Soc., 133(44), $17,521-17,523$.

Stalport, F., P. Coll, C. Szopa, H. Cottin, and F. Raulin (2009), Investigating the photostability of carboxylic acids exposed to Mars surface ultraviolet radiation conditions, Astrobiology, 9(6), 543-549.

Stalport, F., et al. (2012), The influence of mineralogy on recovering organic acids from Mars analogue materials using the "one-pot" derivatization experiment on the Sample Analysis at Mars (SAM) instrument suite, Planet. Space Sci., 67(1), 1-13.

Steele, A., F. M. McCubbin, M. D. Fries, D. C. Golden, D. W. Ming, and L. G. Benning (2012a), Graphite in the Martian meteorite Allan Hills 84001, Am. Mineral., 97(7), 1256-1259.

Steele, A., et al. (2012b), A reduced organic carbon component in Martian basalts, Science, 337(6091), 212-215.

Steele, A., et al. (2013), Organic Carbon Inventory of the Tissint Meteorite, paper presented at Lunar Planet. Sci. XLIV, Abstract \#2854.

Steininger, H., F. Goesmann, and W. Goetz (2012), Influence of magnesium perchlorate on the pyrolysis of organic compounds in Mars analogue soils, Planet. Space Sci., 71(1), 9-17.

Stephan, T., E. K. Jessberger, C. H. Heiss, and D. Rost (2003), TOF-SIMS analysis of polycyclic aromatic hydrocarbons in Allan Hills 84001, Meteorit. Planet. Sci., 38(1), 109-116.

Treger, Y. A., and V. N. Rozanov (1989), The synthesis of organochlorine compounds from one-carbon molecules, Russ. Chem. Rev. Engl. Transl., 58, 84-99. Villaneuva, G. L., M. J. Mumma, R. E. Novak, Y. L. Radeva, H. U. Kaufl, A. Smette, A. Tokunaga, A. Khayat, T. Encrenaz, and P. Hartogh (2013), A sensitive search for organics $\left(\mathrm{CH}_{4}, \mathrm{CH}_{3} \mathrm{OH}, \mathrm{H}_{2} \mathrm{CO}, \mathrm{C}_{2} \mathrm{H6}\right.$, $\left.\mathrm{C}_{2} \mathrm{H}_{4}\right)$, hydroperoxyl $\left(\mathrm{HO}_{2}\right)$, nitrogen compounds $\left(\mathrm{N}_{2} \mathrm{O}, \mathrm{NH}_{3}, \mathrm{HCN}\right)$ and chlorine $\left(\mathrm{HCl}, \mathrm{CH}_{3} \mathrm{Cl}\right)$ on Mars using ground-based high-resolution infrared spectroscopy, Icarus, 222, 11-27.

Yen, A. S., S. S. Kim, M. H. Hecht, M. S. Frant, and B. Murray (2000), Evidence that the reactivity of the Martian soil is due to superoxide ions, Science, 289(5486), 1909-1912.

Yen, A. S., et al. (2006), Nickel on Mars: Constraints on meteoritic material at the surface, J. Geophys. Res., 111, E12S11, doi:10.1029/2006JE002797.

Zent, A. P., and C. P. Mckay (1994), The chemical-reactivity of the Martian soil and implications for future missions, Icarus, 108(1), 146-157.

Zent, A. P., A. S. Ichimura, R. C. Quinn, and H. K. Harding (2008), The formation and stability of the superoxide radical $(\mathrm{O}(2)(-))$ on rockforming minerals: Band gaps, hydroxylation state, and implications for Mars oxidant chemistry, J. Geophys. Res., 113, E09001, doi:10.1029/ 2007JE003001. 